\title{
Celastrol: A Review of Useful Strategies Overcoming its Limitation in Anticancer Application
}

\author{
Jinfeng Shi ${ }^{\dagger}$, Jiaxin $\mathrm{Li}^{\dagger}$, Ziyi Xu, Liang Chen, Ruifeng Luo, Chen Zhang, Fei Gao, \\ Jinming Zhang * and Chaomei Fu *
}

State Key Laboratory of Southwestern Chinese Medicine Resources, Pharmacy School, Chengdu University of Traditional Chinese Medicine, Chengdu, China

\section{OPEN ACCESS}

Edited by:

Muthu Kumaraswamy Shanmugam,

National University of Singapore,

Singapore

Reviewed by:

Bhargav A. Patel,

University of Notre Dame,

United States

Ganapasam Sudhandiran,

University of Madras, India

Lei Wang,

Capital Medical University, China

Peramaiyan Rajendran

King Faisal University, Saudi Arabia

*Correspondence:

Jinming Zhang

cdutcmzjm@126.com

Chaomei Fu

chaomeifu@126.com

${ }^{\dagger}$ These authors have contributed equally to this work and share first

authorship.

Specialty section:

This article was submitted to Pharmacology of Anti-Cancer Drugs, a section of the journal

Frontiers in Pharmacology

Received: 05 May 2020 Accepted: 01 October 2020

Published: 18 November 2020

Citation:

Shi J, Li J, Xu Z, Chen L, Luo R, Zhang

C, Gao F, Zhang J and Fu C (2020)

Celastrol: A Review of Useful

Strategies Overcoming its Limitation in

Anticancer Application.

Front. Pharmacol. 11:558741.

doi: 10.3389/fphar.2020.558741
Celastrol, a natural bioactive ingredient derived from Tripterygium wilfordii Hook F, exhibits significant broad-spectrum anticancer activities for the treatment of a variety of cancers including liver cancer, breast cancer, prostate tumor, multiple myeloma, glioma, etc. However, the poor water stability, low bioavailability, narrow therapeutic window, and undesired side effects greatly limit its clinical application. To address this issue, some strategies were employed to improve the anticancer efficacy and reduce the side-effects of celastrol. The present review comprehensively focuses on the various challenges associated with the anticancer efficiency and drug delivery of celastrol, and the useful approaches including combination therapy, structural derivatives and nano/microsystems development. The specific advantages for the use of celastrol mediated by these strategies are presented. Moreover, the challenges and future research directions are also discussed. Based on this review, it would provide a reference to develop a natural anticancer compound for cancer treatment.

Keywords: celastrol, anticancer activity, combination therapy, analogs of celastrol, nano/micro-formulation

\section{INTRODUCTION}

In the past few decades, the interest in natural medicinal plants and their bioactive molecules has extensively grown, and many of such agents exhibit diverse effects on suppressing the development and progression of tumor, both in vitro as well in vivo (Li, J. et al., 2019; Lagoa et al., 2020; Weng and Goel, 2020). It is widely believed that such substances can provide a plausible alternative to synthetic drugs due to their potency, safety, and lower cost (Hansen et al., 2011). One representative example is celastrol, also named tripterine, which is isolated from the Tripterygium wilfordii Hook F (TWHF) plant, also known as Lei Gong Teng (Thunder God Vine) (Landewé and van der Heijde, 2014). Celastrol is the most abundant and promising bioactive compound derived from TWHF (Corson and Crews, 2007; Liu et al., 2015; Chang et al., 2018), which is a quinone methide triterpenoid and has been voted as one of the top-five promising natural medicine molecules ( $\mathrm{Li}$ and Hao 2019). Celastrol has been found to bear anticancer activities against sundry tumors as evidenced by promising results in multiple preclinical studies, including liver cancer, breast cancer, prostate cancer, leukemia, melanoma, etc. (Kashyap et al., 2018; Yadav et al., 2018).

Recently, data from different tumor cell lines and animal cancer models have suggested that the anticancer properties of celastrol can be attributed to: i) induced apoptosis and autophagy, ii) cell cycle arrest, iii) antimetastatic and anti-angiogenic actions, iv) anti-inflammatory effects, and V) antioxidant activities (Cascão et al., 2017; Kashyap et al., 2018). It could target multiple signaling 
pathways such as reactive oxygen species (ROS)/JNK and Akt/ mTOR (Liu et al., 2019), NF-kb (Chiang et al., 2014), STAT3/ JAK2 (Rajendran et al., 2012), HSP90 (Sreeramulu et al., 2009; Zhang et al., 2009), Cdc37, p23, Iкkb, p-Akt (Kannaiyan et al., 2011), ERa (Jang et al., 2011), etc. In addition, the possible role of celastrol in the epithelial-mesenchymal transition (EMT) has aroused more and more concern (Avila-Carrasco et al., 2019). It has been discovered that celastrol could suppress EMT through up-regulating E-cadherin and down-regulating $\mathrm{N}$-cadherin, Vimentin and Snail (Lin et al., 2015; Divya et al., 2018; Wang L.-P. et al., 2019). The Figure 1 lists some of the key signaling pathway proteins. All these properties make celastrol a promising drug for clinical application of anti-tumor drugs.

Despite the promising anticancer activities of celastrol, the clinical application of celastrol is strictly limited by severe side effects, mainly resulting from its undesirable bio-distribution, as well as various physicochemical and pharmacokinetic limitations, such as low water solubility and bioavailability (Wang et al., 2015; Li et al., 2020). Therefore, celastrol have been investigated to minimize or overcome these limitations (Maysinger et al., 2018; Hu et al., 2019). Raja et al. (2011) designed celastrol in combination with ErbB2-targeted therapeutics for treatment of ErbB2-overexpressing breast cancers. The results indicated celastrol significantly retarded the rate of growth of ErbB2-overexpressing human breast cancer cells in a mouse xenograft model with only minor systemic toxicity. Additionally, some researchers developed water-soluble analogs of celastrol for the translational development of celastrol. NST001A, a sodium salt of celastrol, inhibits the growth of human colon cancer cellColo 205 colon cells in vitro and in vivo (Tang et al., 2014). Furthermore, celastrol-albumin nanoparticles reduce the accumulation of free celastrol in off-target organs and tissues, thus successfully reducing the systemic toxicity of celastrol (Guo et al., 2017). Hence, celastrol has attracted considerable interests in developing new strategies to improve the anticancer efficacy and reduce the side-effects.

The aims of the present review are to summarize and critically analyze the recent development of different novel approaches for use of celastrol that are under cells and animal investigation in regards to minimize or overcome these limitations, as reported in the literature. The useful approaches including combination therapy, structural derivatives and nano/micro-systems development are discussed. The specific advantages for the use of celastrol mediated by these strategies are presented. Moreover, the challenges and future research directions are also discussed. Based on this review, it would provide a reference to develop a natural anticancer compound for cancer treatment.

\section{Limitations Associated With Celastrol Formulation Development}

Although celastrol is very effective in treatment of many types of tumors, and could interact with many cellular targets, it also suffers some limitations such as poor water stability, low bioavailability, narrow therapeutic window, and undesired side effects (Cascão et al., 2017; Hou et al., 2020). These limitations have greatly hindered its clinical application.

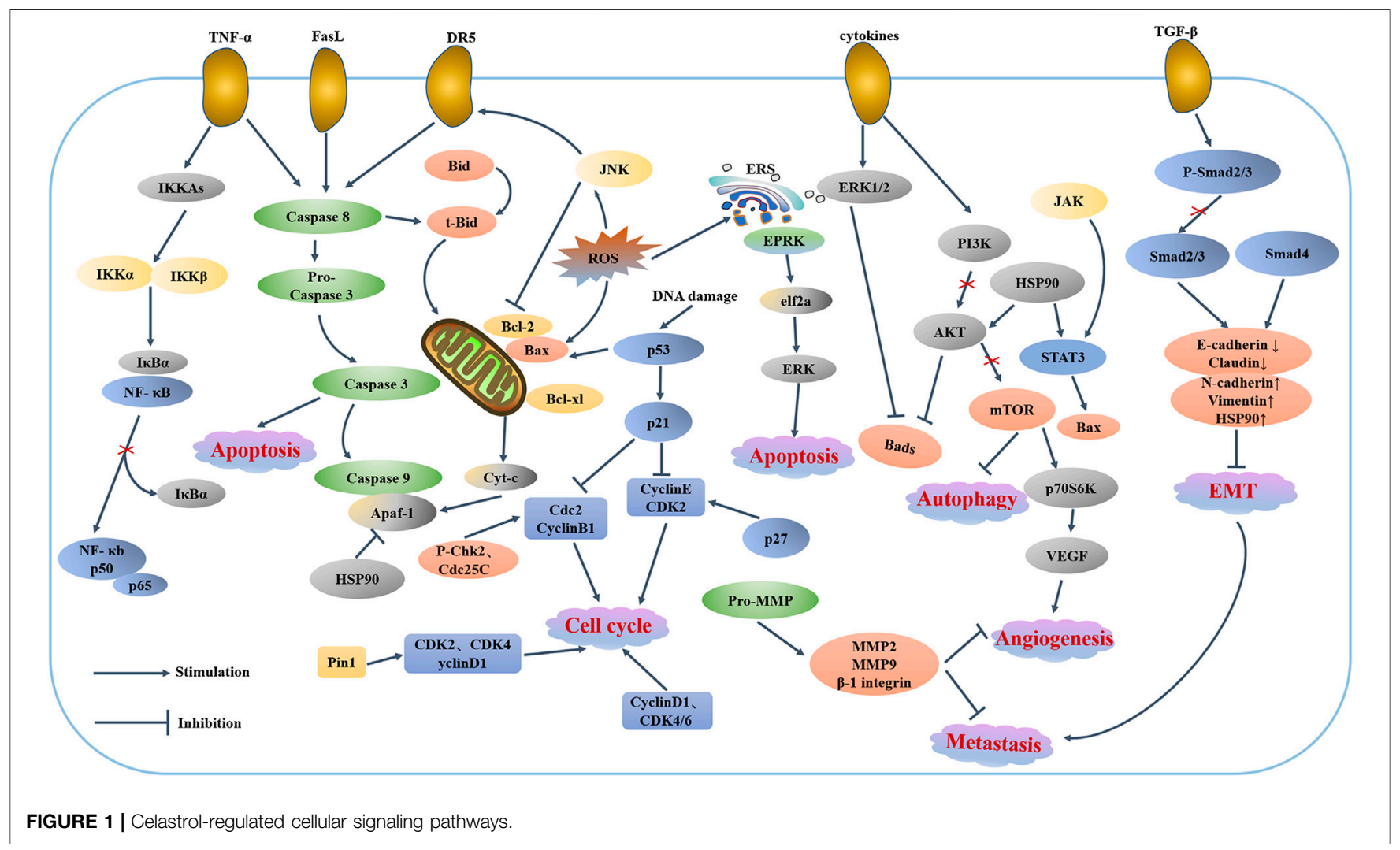


Like so many chemotherapy drugs, celastrol has poor water solubility, which is $13.25 \pm 0.83 \mathrm{mg} / \mathrm{ml}$ at $37^{\circ} \mathrm{C}$ (Qi et al., 2014). Owing to celastrol's poor aqueous solubility, polyoxyethylated castor oil solvent (Cremophor) and ethanol may be used as vehicles. However, it would produce the toxicities associated with Cremophor, etc. (Hoy 2014). Besides, a study from Zhang et al. have demonstrated that oral administration of celastrol in rats results in ineffective absorption into the systemic circulation, with an absolute bioavailability of $17.06 \%$ (Zhang et al., 2012). Li Y. et al. (2012) suggest that besides low aqueous solubility in vivo metabolism and/or tissue distribution might also cause this poor bioavailability.

One great concern regarding the clinical use of celastrol is its narrow therapeutic window of dose together with the occurrence of adverse effects. The effective dose of celastrol against various tumor xenograft model are reported to be around $3-5 \mathrm{mg} / \mathrm{kg}$ (Yang et al., 2006; Zhou and Huang, 2009; Chadalapaka et al., 2012; Liu et al., 2014; Wu et al., 2017). However, lower concentrations immediately lose efficacy and higher concentrations show signs of toxicity (Cascão et al., 2017). Similarly, in an osteosarcoma xenograft mouse model, it was described that treatment with celastrol at 1 and $2 \mathrm{mg} / \mathrm{kg}$ reduced tumor growth (42.9-50.2\%), but it caused 5.7-9\% weight loss in animals (Li et al., 2015). Discrepancies exist in celastrol dosing and toxicity, with data in rodents showing that at $3 \mathrm{mg} / \mathrm{kg}$ there are adverse events and $27 \%$ mortality but other studies showing no toxic effects at this dose. In addition, there are reports showing an $\mathrm{LD}_{50}$ dose of $20.5 \mathrm{mg} / \mathrm{kg}$ and others suggesting a $40 \%$ mortality at $4 \mathrm{mg} / \mathrm{kg}$ (Cleren et al., 2005; Yang et al., 2006; Raja et al., 2011; Li et al., 2013; Konieczny et al., 2014). All of these results indicated that the therapeutic window of celastrol is very narrow. In addition, there are some side effects associated with celastrol, including infertility (Yuan et al., 1995; Bai et al., 2003), cardiotoxicity (Sun et al., 2006; Liu C. et al., 2019), hepatotoxicity (Sun et al., 2014; Jin et al., 2019), hematopoietic system toxicity (Lipsky and Tao, 1997; Kusy et al., 2012) and nephrotoxicity (Wu et al., 2018). Thus, much more attention should be paid for rational use of celastrol and its related preparations. Especially, the possibility of celastrol-drug interaction should be concerned significantly at the therapeutic concentrations.

\section{Strategies for the Use of Celastrol}

To surpass the physicochemical and pharmacokinetic limitations of celastrol and to diminish the effective dose, several methodologies have been tested that can represent useful strategies. Considerable effort has been exerted for the use of celastrol, including combination therapy, structural derivatives of celastrol and nano/micro-systems development (Figure 2).

\section{Combination Chemotherapy in Cancer Treatment}

For a rational design to achieve optimal efficacy and reduce their toxicity, combination strategies used are essential (El Chediak et al., 2017; Gulijk et al., 2018). Lowering the dosage used of celastrol by combining it with agents effectively reduces its related adverse effects. Combination treatment offer opportunities for the translational development of celastrol. At present, the combination therapy of celastrol has been applied to the treatment of various types of cancer. Summary of the antitumor effects of celastrol and agents in vitro and in vivo are listed in Tables 1, 2 .

\section{Combination With Chemotherapeutic Agents Improvement of the Therapeutic Effect}

The combination of chemotherapy drugs can produce an increased or synergistic effect and improve the therapeutic effect. It is the main mode of clinical tumor treatment (Ashton, 2015). Yan et al. (2017) combination celastrol and lapatinib produced strong synergy in growth inhibition and apoptosis in comparison to single-agent treatment in HER2/ neu-overexpressing MDA-MB-453 cells. Recently, the study (Li H. et al., 2018) aimed to investigate the effects of apatinib and celastrol on the proliferation, invasion and apoptosis of human hepatoma Hep3B cells. Finding it can produce a synergistic effect by downregulating the expression of $\mathrm{p}$-Akt and p-ERK, and upregulating the expression of Caspase- 3 and Bax. Celastrol was also described to enhance the anti-liver cancer activity of sorafenib (Zhang R. et al., 2019). Celastrol enhanced the antitumor activity of sorafenib in hepatocellular carcinoma (HCC) tumor cells by suppressing the AKT pathway and VEGF autocrine system, and enhanced the growth inhibition and apoptosis induction of cancer cells by sorafenib both in vitro and in vivo and reduced the dosage of sorafenib needed. Additionally, celastrol combined with epidermal growth factor receptor tyrosine kinase inhibitors significantly suppressed cell invasion of lung cancer cells with a T790M mutation by suppressing the EGFR pathway. And combined therapy can also inhibit tumor growth in vivo (Wang et al., 2018). Researchers investigated that combining ABT-737 and celastrol synergistically suppressed HCC cell proliferation, and induced apoptosis which was accompanied with the activation of caspase cascade and release of cytochrome $c$ from mitochondria. Further study revealed that the enhanced Noxa caused by celastrol was the key factor for the synergy, since small interfering RNA-mediated knockdown of Noxa expression in HCC cells resulted in decreased apoptosis and attenuated antiproliferative effects of the combination. In addition, it unraveled that, upon celastrol exposure, the activation of endoplasmic reticulum stress, specifically, the eIF2a-ATF4 pathway played indispensable roles in the activation of Noxa, which was validated by the observation that depletion of ATF4 significantly abrogated the Noxa elevation by celastrol (Zhu et al., 2012).

The free radical nitric oxide (NO) is known to play a critical role in colorectal cancer growth by promoting tumor angiogenesis. Study indicated that the antiproliferation activity of celastrol was associated with the inhibition of iNOS and eNOS in colorectal cancer cells (Gao et al., 2019). Therefore, treatment with celastrol inhibited colorectal cancer cell growth and migration, and was associated with suppression of the expression of key genes [TYMP, CDH5, THBS2, LEP, MMP9, and tumor necrosis factor $\alpha$ (TNF)] and proteins (IL-1b, MMP-9, PDGF, Serpin E1, and TIMP-4) involved in the angiogenesis 


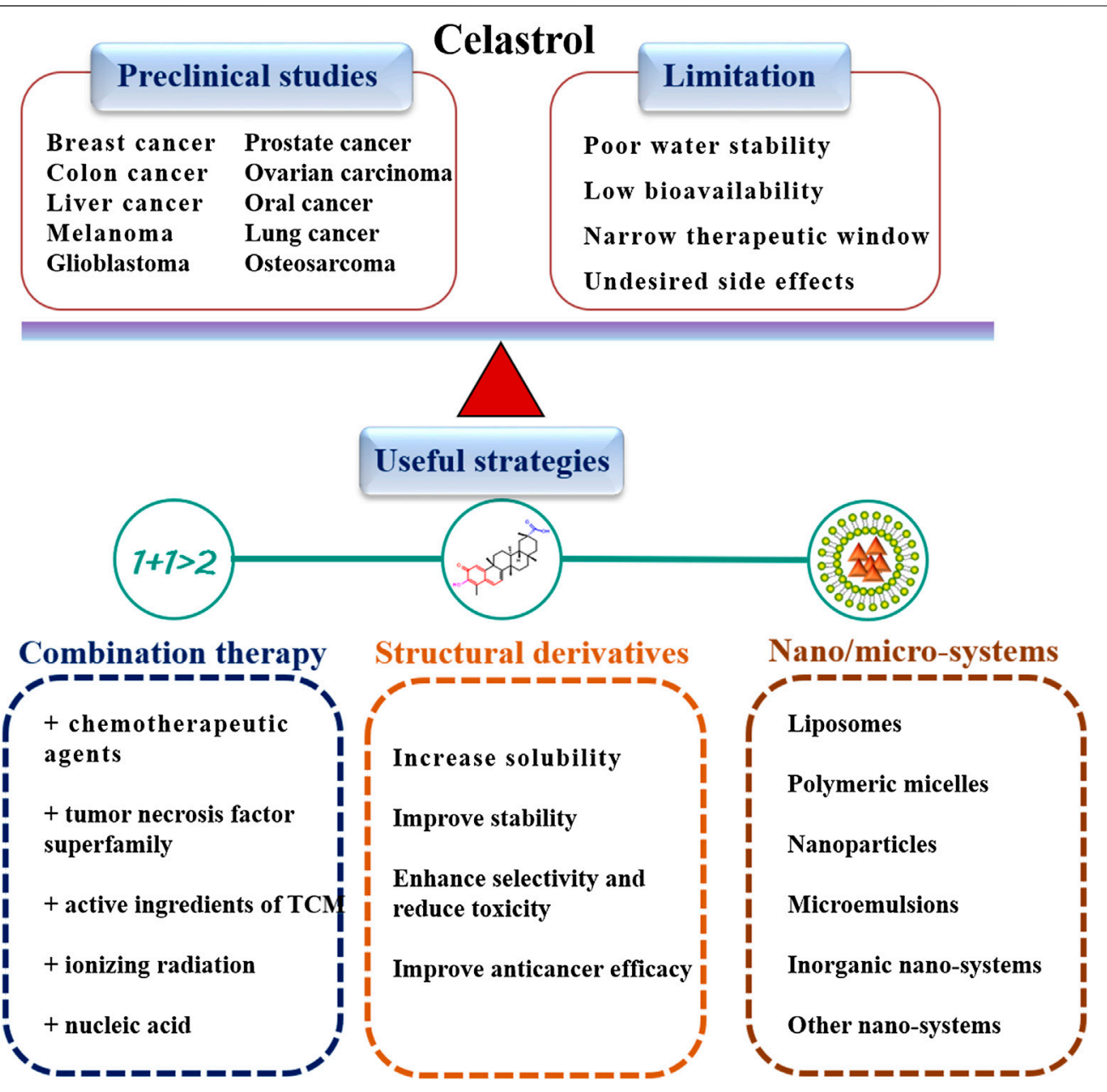

FIGURE 2 | Different type of cancers that celastrol is found to manage. However, the poor water stability, low bioavailability, narrow therapeutic window, and undesired side effects greatly limit its clinical application. To address this issue, some strategies were employed to improve the anticancer efficacy and reduce the sideeffects of celastrol.

pathway. In addition, combinational use of celastrol with 5fluorouracil, salinomycin, 1400W, and L-NIO showed enhanced inhibition of colorectal cancer cell proliferation and migration.

Also, studies have shown that celastrol at high concentration $(>1.0 \mu \mathrm{M})$ induced G2/M arrest and apoptosis with the activation of caspase3/7 in Huh7 cells whereas at low concentration $(<1.0 \mu \mathrm{M})$ had no obvious effects. Low concentration celastrol presented significant combined effects with PHA on Huh7 cells and Huh7 xenografts in terms of growth inhibition, migration inhibition and apoptosis induction (Jiang et al., 2013).

\section{Reduction of Related Adverse Effects of Celastrol}

Lowering the dosage used of celastrol by combining it with chemotherapeutic agents effectively reduces its related adverse effects. During the study carried out by Raja et al. (2011) the researchers observed that the Michael Acceptor functionality in celastrol is important for its ability to destabilize ErbB2 and exert its bioactivity against ErbB2-overexpressing breast cancer cells.
Because celastrol not only induced the expected ubiquitinylation and degradation of ErbB2 and other HSP90 client proteins, but it also increased the levels of ROS. Therefore, celastrol strongly synergized with ErbB2-targeted therapeutics trastuzumab and lapatinib, producing higher level of killing of ErbB2overexperssing breast cancer cell lines $\mathrm{SKBr}-3$ with substantially lower doses of celastrol. Meanwhile, the investigators examined the efficacy of celastrol against ErbB2overexpressing BT-474 cell line in a NOD-SCID xenograft model. Celastrol signifcantly retarded the rate of growth of ErbB2overexpressing human breast cancer cells in vivo with only minor systemic toxicity. Similarly, a study utilizing BT-474 xenograft model determined that combining X66 with celastrol could deplete client protein and inhibit tumor growth, and lead to enhanced activity. No additional toxicity was observed in the cotreatment group as assessed by treatment-related mortality and body weight change (Zhao et al., 2016). As reported, celastrol and cisplatin inhibited the growth of U-2OS cells in a dose-dependent manner. And it induced apoptosis in U-2OS cells via the 
TABLE 1 | Summary of the antitumor effects of celastrol and chemotherapeutic drugs in vitro.

\begin{tabular}{|c|c|c|c|c|c|}
\hline Combined treatment & $\begin{array}{l}\text { Type of } \\
\text { cancer }\end{array}$ & $\begin{array}{l}\text { Cancer cell } \\
\text { lines }\end{array}$ & Pathway & Findings & Ref \\
\hline Lapatinib & Breast cancer & MDA-MB-453 & 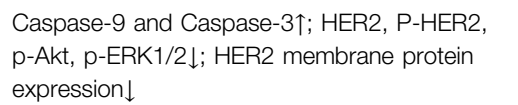 & $\begin{array}{l}\text { Produce strong synergy in growth inhibition and } \\
\text { apoptosis }\end{array}$ & (Yan et al., 2017) \\
\hline Trastuzumab, Lapatinib & Breast cancer & SKBr-3 & 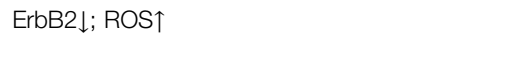 & $\begin{array}{l}\text { Produce higher cytotoxicity with substantially } \\
\text { lower doses of celastrol }\end{array}$ & (Raja et al., 2011) \\
\hline EGFR-TKls & Lung cancer & A549 and $\mathrm{H} 1975$ & EGFR, STAT3, pAKT, and p-ERK $\downarrow$ & Suppress invasion & (Wang et al., 2018) \\
\hline SAHA & Lung cancer; Ovarian cancer & 95-D and SK-OV-3 & E-cadherin $\uparrow$; caspase- 3 and cleaved PARP $\uparrow$ & $\begin{array}{l}\text { Enhance anticancer efficacy; celastrol and SAHA } \\
\text { are reciprocal sensitization }\end{array}$ & (Zheng et al., 2014) \\
\hline Sorafenib & Liver cancer & HepG2 and Hepa1-6 & VEGF and P-AKT $\uparrow$ & $\begin{array}{l}\text { Enhance the growth inhibition and apoptosis } \\
\text { induction; celastrol enhanced the antitumor } \\
\text { activity of sorafenib in HCC tumor cells by } \\
\text { suppressing the AKT pathway and VEGF } \\
\text { autocrine system }\end{array}$ & (Zhang et al., 2019) \\
\hline PHA-665752 & Liver cancer & BEL-7402 and Huh7 & G2/M arrest $\uparrow ;$ caspase $3 / 7 \uparrow$ & Enhance the growth inhibition effect & (Jiang et al., 2013) \\
\hline Apatinib & Liver cancer & Нер3B & p-Akt and p-ERK $\downarrow$; Caspase-3 and Bax $\uparrow$ & $\begin{array}{l}\text { Inhibit the proliferation, migration and invasion } \\
\text { ability and promote the apoptosis }\end{array}$ & (Li, Fan, et al., 2018) \\
\hline ABT-737 & Liver cancer & Bel-7402 and HepG2 & 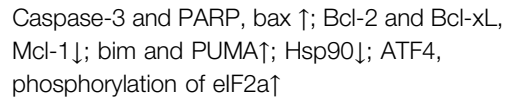 & Upregulate Noxa by ER stress & (Zhu et al., 2012) \\
\hline 17-AAG & GBM & U251N and U343 & $\begin{array}{l}\text { Polyubiquitinated aggregates } \uparrow ; \text { p62 } \\
\text { accumulation } \uparrow\end{array}$ & $\begin{array}{l}\text { Sensitize human glioblastoma to celastrol } \\
\text { treatment }\end{array}$ & (Boridy et al., 2014) \\
\hline Sulfasalazine & Glioma & SNB-19 & G2/M arrest $\uparrow ;$ EGFR $\downarrow$ & $\begin{array}{l}\text { Be effective both as an anticancer drug and as an } \\
\text { agent for sensitizing gliomas to celastrol }\end{array}$ & (Pham et al., 2010) \\
\hline $\begin{array}{l}\text { 5-Fluorouracil, salinomycin, } 1400 \mathrm{~W} \text {, } \\
\text { and L-NIO }\end{array}$ & Colorectal cancer & HT-29 and HCT116 & 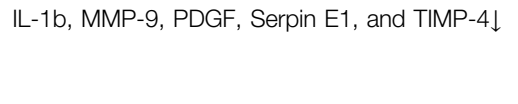 & $\begin{array}{l}\text { Enhance the efficacy of other chemotherapeutic } \\
\text { drugs, including 5-FU, salinomycin, } 1400 \mathrm{~W} \text {, and } \\
\text { L-NIO, in inhibiting CRC cell proliferation }\end{array}$ & (Gao et al., 2019) \\
\hline Paclitaxel & ATC & $8505 \mathrm{C}$ and SW1736 & $\begin{array}{l}\text { Phospho-ERK1/2, phospho-JNK, bip, and cox } \\
2 \uparrow \text { ROS } \uparrow \text {; hsp90, hsp70, bax, DR5, cleaved } \\
\text { caspase-3, and cleaved PARP } \uparrow \text {; ErbB2, Raf- } 1 \text {, } \\
\text { and Bcl2 } \downarrow\end{array}$ & $\begin{array}{l}\text { Celastrol synergized with paclitaxel in induction } \\
\text { of cytotoxicity }\end{array}$ & (Kim et al., 2017) \\
\hline Carboplatin & PHGG & VUMC-HGG-14 & 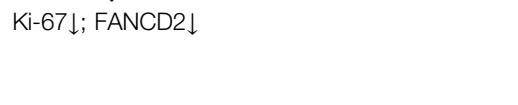 & $\begin{array}{l}\text { Degradation of FANCD2 via celastrol treatment } \\
\text { sensitizes HGGs to carboplatin-mediated DNA } \\
\text { damage }\end{array}$ & (Metselaar et al., 2019) \\
\hline Cisplatin & OS & $\mathrm{U}-2 \mathrm{OS}$ & 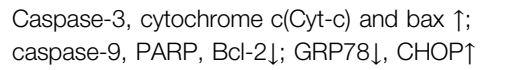 & $\begin{array}{l}\text { Induce apoptosis via the mitochondrial and } \\
\text { endoplasmic reticulum pathways }\end{array}$ & (Wang, Yu, et al., 2019) \\
\hline Bortezomib & Multiple myeloma & U266 & $\begin{array}{l}\text { Caspase- } 3 \uparrow ; N F-k B, C X C R 4 \text { and MMP-9\; IL-6 } \\
\text { and TNF- } \downarrow \downarrow\end{array}$ & $\begin{array}{l}\text { Reduce cell proliferation and enhance apoptosis; } \\
\text { inhibit invasion and migration }\end{array}$ & $\begin{array}{l}\text { (Shanmugam et al., } \\
\text { 2018) }\end{array}$ \\
\hline Temozolomide & Melanoma & SK-MEL-173 & $\begin{array}{l}\text { Ubiquitinated proteins } \uparrow \text {; IкB phosphorylation } \downarrow \text {; } \\
\text { JNK phosphorylation } \uparrow\end{array}$ & $\begin{array}{l}\text { Celastrol may be effective in sensitizing resistant } \\
\text { melanoma cells to the effects of temozolomide }\end{array}$ & (Chen et al., 2009) \\
\hline Daunorubicin & Leukemia & K-562 and Jurkat T & 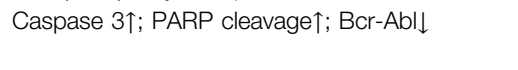 & $\begin{array}{l}\text { Apoptosis induction; sensitize the effect of } \\
\text { chemotherapy in human leukemia cells }\end{array}$ & (Davenport et al., 2010) \\
\hline TNF- $\alpha$ & Breast cancer & MDA-MB-231 & 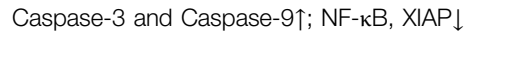 & $\begin{array}{l}\text { Sensitize breast cancer cells MDA-MB-231 to } \\
\text { celastrol }\end{array}$ & (Lu et al., 2014) \\
\hline TRAIL & Lung cancer & A549 & 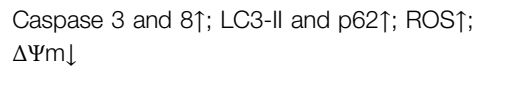 & $\begin{array}{l}\text { Celastrol-mediated autophagy flux inhibition } \\
\text { sensitized TRAIL-initiated apoptosis via } \\
\text { regulation of ROS and } \Delta \Psi m\end{array}$ & $\begin{array}{l}\text { (Nazim, Yin, and Park } \\
\text { 2019) }\end{array}$ \\
\hline
\end{tabular}


TABLE 1 | (Continued) Summary of the antitumor effects of celastrol and chemotherapeutic drugs in vitro.

Combined treatment

Type of

cancer

Cancer cell

lines

Pathway

Findings

Ref

TRAIL

TRAILAPO-2L

GBM

Colon cancer; ovarian carcinoma

Ovary cancer; colon cancer;

Lung cancer

Triptolid

Ellagic acid

Betulinic acid

Lung cancer

Marek's disease

OSCC

Gambogic acid

lonizing radiation

Lung cancer

lonizing radiation

Prostate cancer

Glioblastoma

Prostate cancer

miR-101 mimics

Lung cancer

OS
U87-MG

Activation of caspase-8, caspase-3, and PARP DR5

SW620 and OVCAR8 DR4 and DR5 †; caspase-3, PARP, XIAP

OVCAR-8, SW620 PARP, pro-caspase-3, caspase-9 $\uparrow$

and $95-\mathrm{D}$

$\mathrm{H} 1299$ and $\mathrm{H} 157$

G2/M phase $\uparrow$, Go/G1 phase $\downarrow$, Cdk1, Cyclin and p21个, Cdk2/4/6, Cyclin D/E, pRb, Rb and p27 $\downarrow$; generated cleaved PARP and Caspase-3, bax and bcl-XS/IT, Bcl-2, Mcl-1, survivin an XIAP $\downarrow$; ROS levels $\uparrow$; HSP9O client proteins including survivin, AKT, EGFR $\downarrow$

HOP62 and H1975 LC3-IIT; CIP2A

MSB-1 and BT-474 p65 and Meq $\downarrow$; |kB

\section{Tca8113, TSCC and NF-kappa B $\downarrow$}

NT

NCl-H460 Hsp90: EGFR, ErbB2 and survivin $\downarrow$; p53,

phosphorylating Ser15 and Ser201

PC-3

$\gamma \mathrm{H} 2 \mathrm{AX}$ levels $\uparrow$; Mcl-1 and PARP $\uparrow$

Silence inducible Hsp70

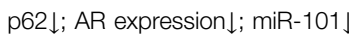

A549 and LTEP-a-2 mTOR, p-p70S6K and p-4EBP1」

Immunotherapy

HOS and U2OS

DR4/5 $\uparrow$; cancer cell lysis by $\gamma \boldsymbol{\delta} T$ cells $\uparrow$
: Celastrol sensitized glioma cells to TRAlL via the (Cha et al., 2019) death receptor pathway; DR5 plays an important

role in the effects of this cotreatment

Enhance mRNA and protein expression of DR4 (Zhu et al., 2010b) and DR5 play prominent roles in the sensitization

of celastrol to TRAIL/Apo-2l-induced apoptosis,

in a p38 MAPK-independent manner

Enhance anticancer activities by the prompt (Zhu et al., 2010a)

onset of caspase mediated apoptosis

Induce G2/M cell cycle arrest; induce cancer cell (Jiang et al., 2015)

optosis; ROS is critical for the synergistic

anticancer effects

Enhance autophagy and down-regulate CIP2A (Duan et al., 2019) Anti-proliferation and apoptosis; inhibition of NF- (An, Li, and Zhang кB transcriptional activity; target antiapoptotic 2015) gene Meq

Inhibit the proliferation and induce the apoptosis (He et al., 2009)

Enhancement of radiation sensitivity

(Lee et al., 2011)

Sensitize PC-3 cells to radiation both in vitro and (Dai et al., 2009) in vivo by impairing DNA damage processing and

augmenting apoptosis

Reduce cell viability, and enhance (Matokanovic et al.

antiproliferative effects 2013)

Autophagy inhibition by miR-101 mimic was (Guo et al., 2015)

found to enhance the cytotoxic effect of celastrol

in prostate cancer cells

Enhance the sensitivity of lung adenocarcinoma ( $L i$, Sun, et al., 2018) cells to celastrol

In combination with immunotherapy approaches (Li et al., 2016) employing adoptive $\boldsymbol{\gamma} \boldsymbol{\delta}$ T cell transfer

TNF-a, tumor necrosis factor $\mathbf{a}$; TRAIL, tumor necrosis factorrelated apoptosis-induced ligand; EGFR-TKI, epidermal growth factor receptor tyrosine kinase inhibitor; SAHA, suberoylanilide hydroxamic acid; 17-AAG, 17-N-Alylamino-17demethoxygeldanamycin; ATC, anaplastic thyroid carcinoma; pHGG, pediatric high-grade gliomas; OS, osteosarcoma; OSCC, oral squamous cell carcinoma; GBM, glioblastoma multiforme; DR5, death receptor 5; PARP, poly(adenosine triphosphate-ribose) polymerase; ROS, reactive oxygen species; TRAILAPO-2L, tumor necrosis factor (TNF) a-related apoptosis-inducing ligand; $\triangle \Psi m$, mitochondrial membrane potential. 
TABLE 2 | Summary of the antitumor effects of celastrol and chemotherapeutic drugs in vivo.

\section{Treatment \\ Type of cance \\ Animal model}

Findings

Ref

Carboplatin $\quad$ PHGG $\quad$ Female athymic nude mice were stereotactically injected VUMC HGG-14 cells $(50 \times 104$ cells in $5 \mu$ L) into the striatum

Bortezomib

Multiplemyeloma

Male athymic balb/c nude mice were implanted with $2 \times 106$ cells with human MM U266 cell lines subcutaneously

EGFR-TKls Lung cancer

SAHA

Lung cancer

BALB/c nude mice were subcutaneously injected with $2 \times 106$ H1975 lung carcinoma cells

Human lung cancer 95-D xenografts were established by subcutaneously inoculating $5 \times 106$ cells into nude mice

Sorafenib

Liver cancer

PHA-665752

Liver cancer

The C57bl/6 mice were injected subcutaneously with Hepa1-6 single-cell suspension cells $(2 \times 107 / \mathrm{ml})$ into the right flank

Male nude mice were inoculated subcutaneously with human liver cancer cell lines Huh7

Trastuzumab, Lapatinib Breast cancer

Female NODSCID mice received sub-cutaneous $17 \beta$-estradiol pellet $(0.72 \mathrm{mg} /$ day), 2 weeks prior to injection of $5 \times 106$ BT-474 cells resuspended in $4 \%$ Matrigel

X66

Breast cancer

TRAILAPO-2L

Lung cancer

Female Balb/cA-nude mice were implanted subcutaneously with

BT-474 cells in the right flank

Human lung cancer 95 -D xenografts were established by $5 \times 106$ cells subcutaneously inoculated in nude mice

TRAILAPO-2L Colon cancer

Triptolide

Lung cancer

Human colon cancer SW620 xenografts were established by $5 \times$

106 cells subcutaneously inoculated in nude mice

Balb/c nude mice were injected subcutaneously with H1299 or $\mathrm{H} 157$ cells $(3 \times 106$ in $100 \mu \mathrm{L}$ of medium) under the shoulder

Ellagic acid

Lung cancer

miR-33a-5p

Lung cancer

Female BALB/C nude mice were injected HOP62 cells $(1 \times 106)$ subcutaneously into the right rear flank

BALB/c-nu/nu male mice were injected subcutaneously with LTEP-a-2 cells into the right or left flanks

lonizing radiation Prostate cancer

Female athymic NCr-nu/nu mice were inoculated subcutaneously on both sides of the lower back above the tail with $3 \times 106$ cells/

$0.2 \mathrm{ml}$ of PC-3 cells

lonizing radiation Lung cancer
Prolong survival of pHGG-bearing mice; combination therapy using celastrol and carboplatin might serve as a clinically relevan strategy for the treatment of pHGG

Augmented bortezomib induced inhibition of tumor growth; No

any obvious side effects

Inhibit tumor growth

Tumor growth inhibition without increased toxicity

Enhance the antitumor activity and reduce the dosage of sorafenib

The combination of celastrol and PHA could effectively inhibit c-met-deficient hepatocellular carcinoma cells growth, migration and apoptosis

Retard the rate of growth of ErbB2- overexpressing human breast cancer cells in a mouse xenograft model with only minor systemic toxicity

Enhance anti-tumor activity, with no additional toxicity

Increase the in vivo antitumor capacities without increasing the toxicities caused by the celastrol

Inhibit tumor growth

Inhibit the growth of tumors without obvious toxicity

Metselaar et al., 2019)

(Shanmugam et al., 2018)

(Wang et al., 2018)

(Zheng et al., 2014)

(Zhang et al., 2019)

(Jiang et al., 2013)

(Raja et al., 2011)

(Zhao et al., 2016)

(Zhu et al., 2010a)

(Zhu et al., 2010b)

(Jiang et al., 2015)

(Duan et al., 2019) weight

miR-33a-5p inhibited the proliferation of lung adenocarcinoma cells, enhanced the antitumor effect of celastrol, and improved sensitivity to celastrol by targeting mTOR

Inhibit PC-3 tumor growth without obvious systemic toxicity

(Li Y. J. et al., 2018)

(Dai et al., 2009)

Radiosensitizing agent celastrol has therapeutic effects when combined with ionizing radiation
Nude mice were injected with $5 \times 10^{7}$ A549 cells in the back subcutaneously

EGFR-TKI, epidermal growth factor receptor tyrosine kinase inhibitor; SAHA, suberoylanilide hydroxamic acid; TRAILAPO-2L, tumor necrosis factor (TNF) $\alpha$-related apoptosis-inducing ligand; X66, 4-(2-((1H-indol-3-yl)methylene)hydrazinyl)N-(4-bromophenyl)-6-(3,5- dimethyl-1H -pyrazol-1-yl)-1,3,5-triazin-2-amine. 
mitochondrial and endoplasmic reticulum pathways (Wang Q. et al., 2019). Celastrol significantly reduced cell proliferation and enhanced apoptosis when used in combination with bortezomib and upregulated caspase- 3 in these cells (Shanmugam et al., 2018). Celastrol also augmented bortezomib induced inhibition of tumor growth in statistically significant manner. Moreover, it did not notice any obvious side effects from the administration of celastrol. Hence, published data suggest that the combination therapy of celastrol can play the role of increasing therapeutic effect and reducing toxicity.

\section{Overcoming Multidrug Resistance}

In addition, due to the different mechanism of action of chemotherapy drugs, it could prevent the occurrence of multidrug resistance (MDR). In a study (Pham et al., 2010), it was shown that sulfasalazine, a Food and Drug Administrationapproved drug, may be effective both as an anticancer drug and as an agent for sensitizing gliomas to celastrol. Similarly, a study emphasized that targeting proteotoxic stress responses by inhibiting HSP90 with 17-AAG sensitized human glioblastoma to celastrol treatment, thereby serving as a novel synergism to overcome MDR (Boridy et al., 2014). Research reported that E-cadherin expression, as a classic marker that is used to define either epithelial or mesenchymal characteristics, was reduced in celastrol-resistant SK-OV-3 cells (Hayashi et al., 2010). In another study showed that the synergistic anticancer effects of celastrol and suberoylanilide hydroxamic acid (SAHA) due to their reciprocal sensitization, which was simultaneously regulated by NF-кB and E-cadherin. (Zheng et al., 2014). So SAHA increased the expression of E-cadherin which could significantly augmented the ability of celastrol monotherapy to induce apoptosis. Due to the sensitivity of celastrol to SK-OV-3 cells is improved, it can indirectly play the role of anti-MDR. Moreover, the enhanced anticancer efficacy of celastrol combined with SAHA was validated in a human lung cancer 95-D xenograft model without increased toxicity. The findings not only open new opportunities for the clinical development of SAHA but should also motivate the clinical investigation of celastrol, which has been hampered by its toxicity.

On the other hand, celastrol, as a blood-brain barrierpenetrable compound, could degrade FANCD2, to sensitize glioma cells to the archetypical DNA-crosslinking agent carboplatin in vitro in seven patient-derived pediatric highgrade gliomas (pHGG) models (Metselaar et al., 2019). Therefore, combination therapy using celastrol and carboplatin might serve as a clinically relevant strategy for the treatment of pHGG.

\section{Combination With Tumor Necrosis Factor Superfamily}

Tumor necrosis factor superfamily can specifically induce programmed apoptosis of tumor cells, but it is not toxic to normal cells (Aggarwal et al., 2012). Therefore, it has become a hot research field of anti-tumor in recent years. In a study, it has been showed that TNF- $\alpha$ could sensitize breast cancer cells MDAMB-231 to celastrol through inhibiting the activation of $\mathrm{NF}_{-\kappa} \mathrm{B}$ signaling, leading to XIAP inhibition with subsequent upregulation of caspase- 3 and caspase- 9 activities ( $\mathrm{Lu}$ et al.,
2014). Thus, it indicated when combined with the natural proteasome inhibitors, celastrol, the anti-cancer activities of TNF- $\alpha$ can enhance. In addition, Nazim et al, (2019) have shown that treatment with celastrol caused an increase in microtubule-associated proteins $1 \mathrm{~A} / 1 \mathrm{~B}$ light chain $3 \mathrm{~B}-\mathrm{II}$ and p62 levels, whereas co-treatment of celastrol and tumor necrosis factorrelated apoptosis-induced ligand (TRAIL) increased active caspase- 3 and caspase- 8 levels compared with the control, confirming inhibited autophagy flux. Therefore, the combined use of TRAIL with celastrol may serve as a safe and adequate therapeutic technique for the treatment of TRAILresistant lung cancer. Other studies (Cha et al., 2019) demonstrated that celastrol sensitized glioma cells to TRAIL via the death receptor pathway and that DR5 played an important role in the effects of this co-treatment. It indicates that this co-treatment is a promising tumor-killing therapeutic strategy with high efficacy and low toxicity. Zhu et al. (2010a), Zhu et al. (2010b) reported combining TRAIL/APO-2L and celastrol could produce synergistic anticancer capabilities. On the one hand, the enhanced mRNA and protein expression of DR4 and DR5 play prominent roles in the sensitization of celastrol to TRAIL/Apo-2L-induced apoptosis, in a p38 MAPK-independent manner. On the other hand, these enhanced anticancer activities were accompanied by the prompt onset of caspase mediated apoptosis. It opens new opportunities to enhance the effectiveness of future treatment regimens using TRAIL/APO-2L.

\section{Combination With Active Ingredients of Traditional Chinese Medicine}

$\mathrm{He}$ and co-workers found that the combination of gambogic acid and celastrol has a synergistic antitumor effect for treating oral squamous cell carcinoma. The minimal cytotoxic dose of celastrol was able to effectively suppress the gambogic acid-induced NFkappa B pathway activation (He et al., 2009). Moreover, active components from the same herb can synergize with other compounds isolated from the same herb (Zhou et al., 2016). For example, combination treatment of triptolide and celastrol synergistically inhibits cell growth, induces cell cycle arrest at G2/ $M$ phase and apoptosis, and increases intracellular ROS accumulation in many types of cancer cells, including H1299 and H157 lung cancer cells (Jiang et al., 2015).

It has also been determined that $10-50 \mu \mathrm{M}$ ellagic acid significantly enhanced the effects of celastrol (at relatively low concentrations) on lung cancer cells by inducing autophagy. It also found that combined treatment resulted in significant inhibitory effects on tumor growth compared with either monotherapy, without a reduction in body weight. These data indicate that the combination of ellagic acid and celastrol exerts synergistic anti-lung cancer effects both in vitro and in vivo (Duan et al., 2019). Another study (An et al., 2015) suggested that the combination of betulinic acid and celastrol at lower concentration may produce a synergistic inhibitive effect on MSB-1 cells. Besides, betulinic acid and celastrol of the above concentrations are nontoxic to non-tumorous chicken embryo fibroblasts and selective to MSB-1 cells. Thus warrants further investigation for its potential clinical applications. 


\section{Combination With lonizing Radiation}

It has also been found that celastrol may be considered an effective radiosensitizer acting as an inhibitor of Hsp90 and a p53 activator. The two activities could be applicable to a broad range of cancer cells with either wild-type or mutant $\mathrm{p} 53$ because either activity could be effective for the enhancement of radiation cell killing (Lee et al., 2011). The study showed that the novel radiosensitizing agent celastrol had therapeutic effects when combined with ionizing radiation (IR) in vitro and in vivo (Jun et al., 2017). Besides, diffusion-weighted magnetic resonance imaging was a useful noninvasive tool to monitor the effects of celastrol by assessing cellularity changes and sequential therapeutic responses. Furthermore, when combined with IR, celastrol significantly prolonged the presence of IRinduced $\gamma \mathrm{H} 2 \mathrm{AX}$ and increased IR-induced apoptosis (Dai et al., 2009). Celastrol, combined with fractionated radiation, significantly inhibited PC-3 tumor growth in vivo without obvious systemic toxicity. Therefore, the research outputs celastrol sensitized PC-3 cells to radiation both in vitro and in vivo by impairing DNA damage processing and augmenting apoptosis.

\section{Combination With Nucleic Acid}

The miRNA is a short endogenous noncoding RNA and responsible for the modulation of cell migration, proliferation, programmed cell death, and cell differentiation by directly binding to target gene mRNA and further leading to mRNA degradation and translational inhibition via imperfect base pairing to the $3^{\prime}$-UTR (Huntzinger and Izaurralde, 2011). Besides, miRNAs can also function as oncogenes or tumor suppressor genes in carcinogenesis, cancer progression, and metastasis (Huang et al., 2017). Guo et al. (2015) found that autophagy inhibition by miR-101 mimic could enhance the cytotoxic effect of celastrol in prostate cancer cells. Similarly, findings also suggested that miR-33a-5p could inhibit the proliferation of lung adenocarcinoma cells, enhance the antitumor effect of celastrol, and improve sensitivity to celastrol by targeting $\mathrm{mTOR}$ in lung adenocarcinoma in vitro and in vivo (Li Y. J. et al., 2018). In addition to this, inducers of heat shock protein 70 (Hsp70) commonly promote cancer cell viability whereas inhibitors of Hsp90 reduce it. Therefore, in order to silence inducible Hsp70 and to promote celastrolinduced tumor cell death, Matokanovic and co-colleagues prepared Hsp70 siRNA loaded chitosan-TPP carriers and it is found that silencing of Hsp70 by chitosan-TPP-Hsp70 siRNA treatment significantly reduced cell viability, and enhanced antiproliferative effects of celastrol in glioblastoma cells (Matokanovic et al., 2013). Thus combination of nucleic acid with celastrol may represent a promising therapeutic approach for treating cancers.

\section{Structural Derivatives of Celastrol}

Celastrol has poor water-solubility, short half-life, narrow therapeutic window and low bioavailability, which seriously affect its clinical application. With the development of synthetic technology, the structure of celastrol was modified by chemical means and the derivatives with biological activity were synthesized. At present, it is mainly by modifying the A/B ring and position $\mathrm{C}-20$ (Figure 3 ) to improve the properties of the drug and enhance the anti-tumor activity.

\section{Increase Solubility to Enhance Antitumor Effects}

Celastrol has poor water-solubility, which greatly limits its bioavailability. Therefore, enhancing the solubility of celastrol is conducive to improving the antitumor effects. Generally speaking, the solubility of compound is directly related to the number of polar groups. By introducing hydrophilic groups such as amino, hydroxyl, amide, and sulfonic acid, the solubility is improved and the efficacy is studied (Cai et al., 2016) (Figure 4). Klaić et al. (2012) converted carboxylic acid functional groups into amides, of which compound (1) can enhance the induction of heat shock response of the matrix, due to the hydrophilic groups increasing solubility and permeability. Tang and his teamworkers (Tang et al., 2015) synthesized a series of celastrol derivatives through amide reaction at the C-20 site, these compounds are effective against SGC-7901, SMMC-7721, MGC-803 and HepG 2 cell lines proliferation. They found that derivatives (2) and (3) contained hydrophilic groups to improve solubility and then had high antitumor effects. Their inhibitory $\mathrm{IC}_{50}$ on telomerase was 0.11 and $0.34 \mathrm{mM}$, which increased the anti-proliferation activity of HepG 2 cells by 6.6 times and 14.3 times. In this study, the tumor target telomerase was associated with celastrol for the first time, and celastrol derivatives potentially inhibiting telomerase were synthesized. Other researchers have modified amino acids, amines, and piperazine on C-20 to synthesize a series of celastrol derivatives with amide bonds, which has better solubility and penetration. Such as amino acids modified compound (4) has higher anticancer activity in AGS cell line with its IC $_{50}$ value concentration of $0.44 \mu \mathrm{M}$, while the concentration of compound (5) in vivo was higher than that of celastrol. Besides, compounds (6) and (7) have a strong antiproliferative activity of Hela and A549 cell lines, which are 5 and 10 times that of celastrol (Zhang H.-J. et al., 2018; Pang et al., 2018; Wang G. et al., 2019). On the other hand, the water solubility of compound (8) is 35 times that of celastrol and its tumor suppressive activity is higher than celastrol against the PANC-1 cell line and the human lung cancer (paclitaxelresistant) A549 cell line (Jiang et al., 2016).

In addition, Zeng and Tang synthesized compounds (9) and (10), through the introduction of C-6 sulfonamide salt, which greatly increases its solubility. The results showed it could significantly inhibit tumor growth at low concentrations (Zeng et al., 2012; Tang et al., 2014). Meanwhile Shan and his team (Shan et al., 2017) treated amino acid methyl hydrochloric acid on the C-3 and C-20 position, in which compound (11) was introduced by piperazine to expand the electron cloud density of ring $\mathrm{A}$ and reduce the toxicity during in vivo experiment by intragastric administration.

\section{Increase Stability to Enhance Antitumor Effects}

Celastrol is easy to polymerize and unstable in acidic or alkaline environment, in which ring $\mathrm{A}$ is prone to ring opening and rearrangement (Shi 2015). Researchers modified the structure of celastrol to improve its stability (Figure 5). It was found that PEG 

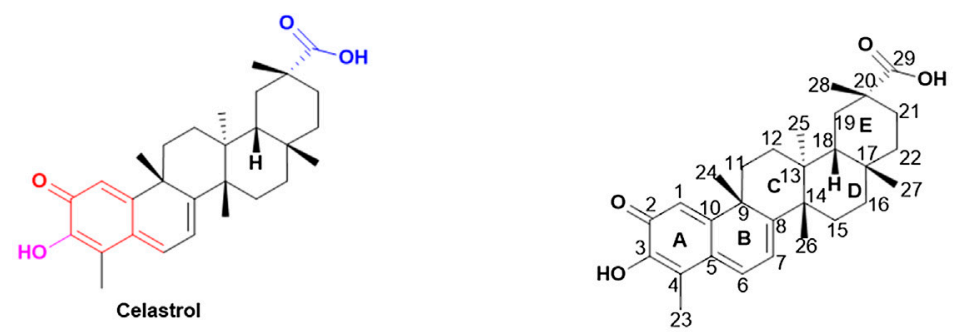

- $\mathrm{A} / \mathrm{B}$ ring is the group related to the activity; $\mathrm{C}-2$ and $\mathrm{C}-3$ can be modified to improve the activity C-6 mainly introduces sulfonic acid and indole through nucleophilic reaction

- C-20 carboxyl group is the main modifying group, and its physicochemical properties can be improved mainly through esterification reaction and amide reaction

FIGURE 3 | The structure of celastrol and its some important properties.

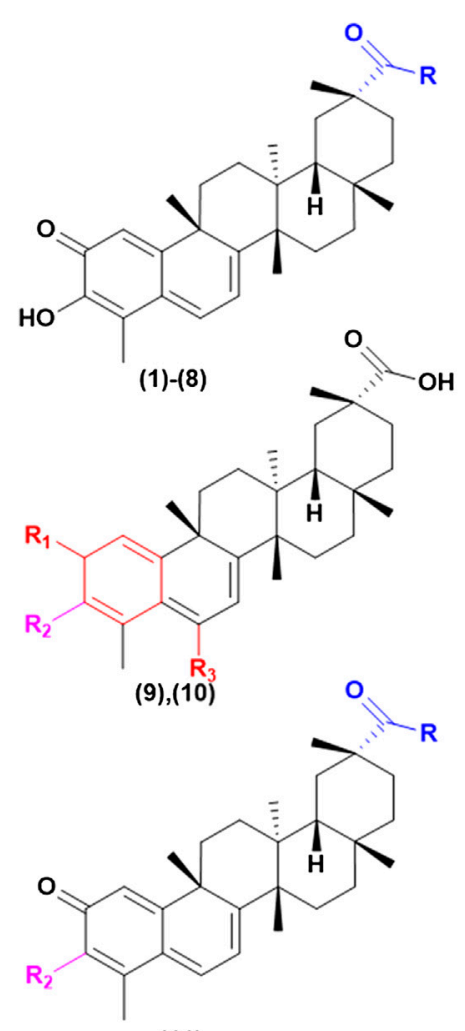

(11)
(1): $\mathrm{R}=\mathrm{NH}_{2}$

(2): $\mathrm{R}=\mathrm{NHCH}_{2} \mathrm{CH}_{2} \mathrm{OH}$

(3): $\mathrm{R}=\mathrm{NH}-i$-propanol

(4): $: \mathbf{R =}$<smiles>COC(=O)C(=O)C(Cc1c[nH]c2ccccc12)NC#[V]</smiles>

(6): $R=$<smiles>COC(=O)C(C)NC(C)(C)C</smiles><smiles>CCOC(=O)C(CO)NC(C)=[Te]</smiles>

$(8): R=$<smiles>CN1CCN(CCCNC(C)(F)F)CC1</smiles>

(9): $\mathrm{R}_{1}=\mathrm{R}_{2}=\mathrm{OH} \quad \mathrm{R}_{3}=\mathrm{SO}_{3} \mathrm{Na}$

(10): $\mathrm{R}_{1}=\mathrm{R}_{2}=\mathrm{COOCH}_{3} \quad \mathrm{R}_{3}=\mathrm{SO}_{3} \mathrm{Na}$<smiles>[14CH2][14CH2]OCc1ccccc1</smiles>

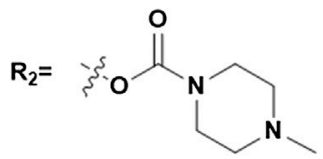

FIGURE 4 | Increase solubility to enhance antitumor effects.

has the function of long circulation, and the stability can be improved by linking celastrol to PEG. Li and other colleagues ( $\mathrm{Li}$ et al., 2017) reported that celastrol and ginsenoside Rh2 were connected through PEG to synthetic compound (12), which could form micelles with a half-life increasing 1.03-2.44 times. The A549 cell absorption rate increased by 5.8 times, which made it higher cell uptake, stronger induction of apoptosis and antiproliferation activity compared with celastrol. In another study,
Shan and colleagues (Shan et al., 2019) studied celastrol derivatives by combining carboxyl groups on C-20 with PEG covalent bonds, the compound (13) can form micelles in water, which greatly improve the stability of celastrol. At the same time, through the experiment of A549 xenograft nude mice, it was proved that compound (13) has higher activity and safety than celastrol. Carbamate chemistry is a key structural motif for many marketed drugs and precursors because of its stability and ability 

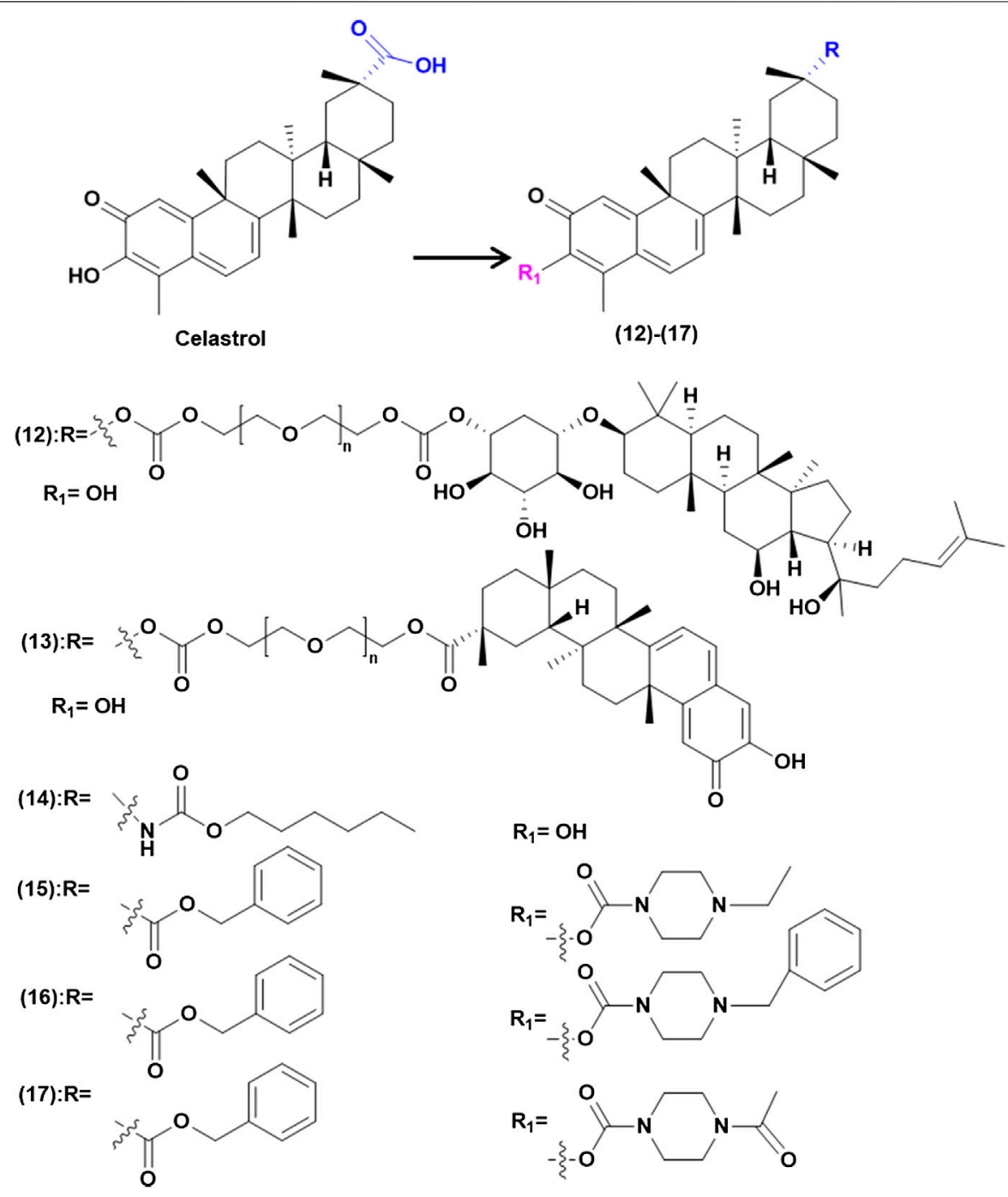

FIGURE 5 | Increase stability to enhance antitumor effects.

to permeate cell membranes (Ghosh and Brindisi, 2015). So Figueiredo and others (Figueiredo et al., 2017) synthesized a series of diacetic carbamate derivatives by C-20 modification with celastrol, among which compound (14) had high activity. Meanwhile Shan and his team (Shan et al., 2017) treated amino acid methyl hydrochloric acid on the C-3 and C-20 position, in which compound (15)-(18) showed higher inhibition rate and better safety than celastrol during in vivo experiment by intragastric administration.

\section{Improve Selectivity to Enhance Antitumor Effects and Reduce Toxicity}

Celastrol has the duality of "toxin-effect" and its active part is also the toxic part. By enhancing the selectivity of celastrol, the toxicity can be greatly reduced and the property of drug can be improved (Figure 6). Figueiredo's team (Figueiredo et al., 2017) modified the C-20 position with urea and conducted in vitro experiments on SKOV-3 cells as well as on non-tumor BJ cells, shown that the activity of compound (19) in SKOV-3 cells is six times that in non-tumor BJ cells. The result indicated that the introduction of urea could greatly improve its selectivity and its activity is three times that of celastrol. They then modified C-20, C-2 and C-3 positions to synthesize celastrol derivatives of diacetate carbamate and A/B epoxy, compared with the parent compound, all diacetate showed higher cytotoxic activity to MIA PaCa-2. Among these compounds, carbamate derivative (20) has the highest activity and the lowest $\mathrm{IC}_{50}$. It has the activity of inhibiting the proliferation of various tumor cells. Besides, in vitro experiments showed that compound (20) had obvious selectivity between tumor cells and non-tumor human BJ cells. In addition, SKOV-3 cells were more sensitive to compound (20) than other tested cancer lines, which showed a 7-fold increase in tumor sensitivity to nontumor fibroblast cell lines. Liu (2017) innovatively linked the nucleoside aptamer to C-20 through celastrol to synthesize compound (21). Through in vitro cytotoxicity experiments on PANC-1 and normal human liver 


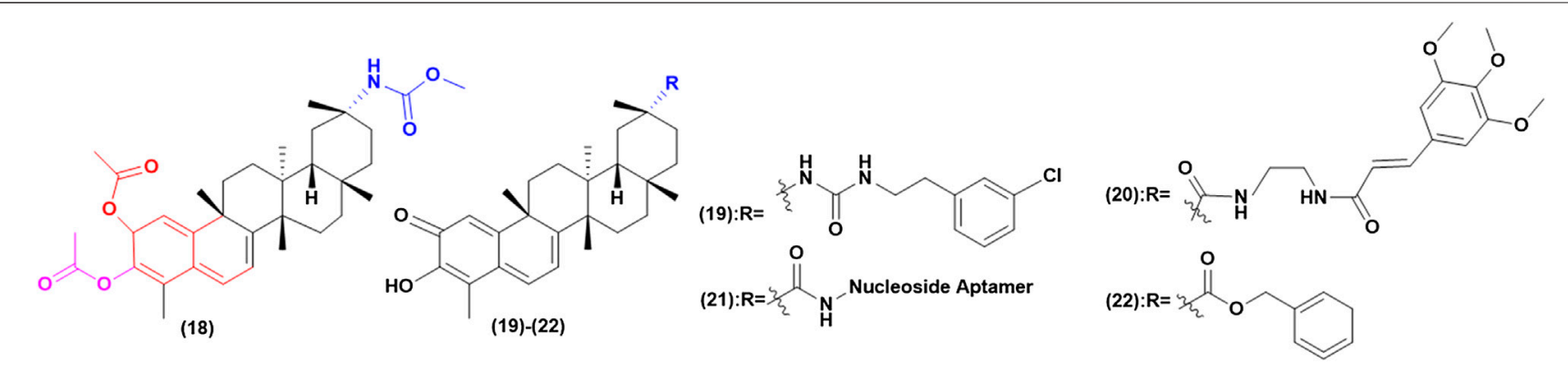

FIGURE 6 | Improve selectivity to enhance antitumor effects and reduce toxicity.

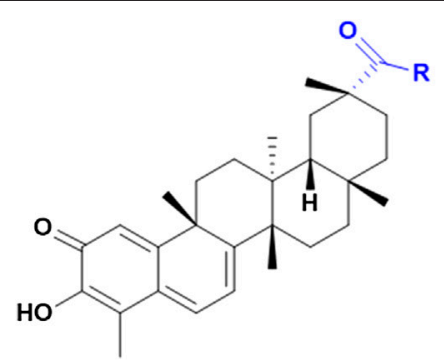

(23),(24)

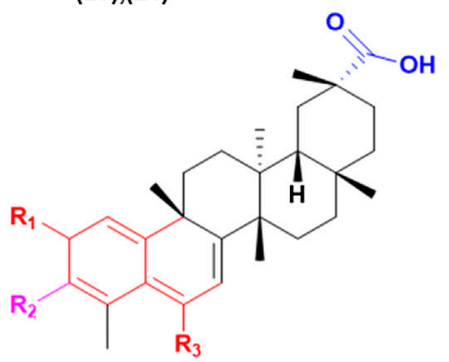

(25),(26)
(25): $\mathrm{R}=\mathrm{OCH}_{3} \quad \mathrm{R}_{1}=\mathrm{R}_{2}=\mathrm{OCH}_{3}$

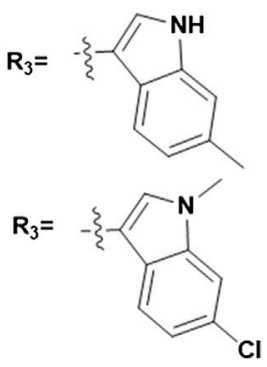

FIGURE 7 | Other structural modifications to enhance biological activity.

cell line, it was proved that compound (21) has higher antiproliferative and growth activities, has less liver toxicity and high selectivity compared with celastrol. It was found that compound (22) were synthesized by linking with aromatic groups or cinnamamide, and in vitro experiments showed that its selective activity was increased ( $\mathrm{Li}$ X. et al., 2019). Some scholars introduced aromatic substituted phenyl group to synthesize compound (23) and found that it has higher anticancer activity and lower cytotoxicity to normal cells (Wei et al., 2014; Shan et al., 2017).

\section{Other Structural Modifications to Enhance Biological Activity}

In addition to the above, there are other structural modification derivatives that enhance biological activity (Figure 7). The inhibition of celastrol on protein HSp90 was found to have significant stereospecific specificity (Klaic et al., 2011), while modifications to C-20 and C-6 whose specific substituents can affect activity (Shan et al., 2017). Xu et al. (2019) adopted the natural product hybridization strategy, and the carboxyl group 29 was modified by methylferulic acid and its derivatives through different ligands. In particular, compound (24) had the ability to disturb the Hsp90-CDC37 complex stronger than celastrol, and its antitumor capacity was about 5 times that of celastrol.

(Li N. et al., 2018) used esterification and imitization at position C-20 to introduce furoxy NO donors into celastrol to synthesize celastrol/furoxy hybrids. Their antiproliferative to A549, HOS, MCF-7 and HepG2 were evaluated. The results showed it has higher biological activity. Moreover, it was found that anti-proliferative activity was positively correlated with the amount of NO released. In addition, the introduction of different types of NO donors has different effects on the structure of celastrol. In this study, compound (25) was screened out to show extremely strong activity in A549 cells 


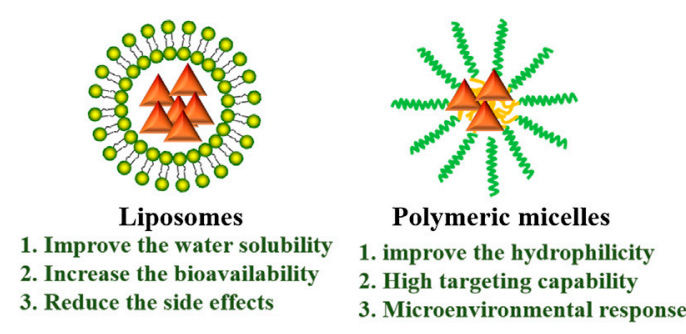

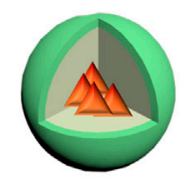

Polymeric nanoparticles

1. Improve pharmacokinetics properties

2. Improve biodistribution

3. Alleviate the adverse effect

4. High targeting capability

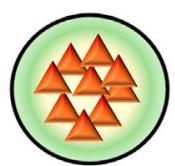

Solid lipid nanoparticles

1. Improve the hydrophilicity

2. Enhance the oral bioavailability

3 . Reduce the side effects

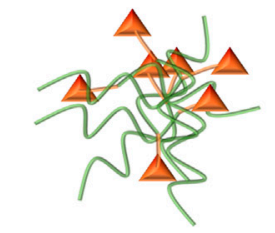

Polymer-drug conjugates

1. Microenvironmental response

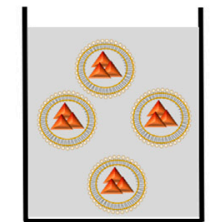

Microemulisons

1. Alleviate the adverse effect

2. High targeting capability

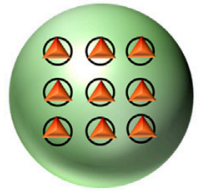

Inorganic systems

1. Reduce the side effects

2. High targeting capability

FIGURE 8 | Different types of celastrol nano/micro-systems with their major advantages.

$\left(\mathrm{IC}_{50}=0.48 \pm 0.06 \mathrm{M}\right)$, greatly optimizing the activity of celastrol. Further mechanism studies showed that it could inhibit the activity of Hsp90 well and release high levels of NO together to induce apoptosis.

Additionally, some scholars have modified C- 6 to improve the biological activity of celastrol. Such as, C-6 indole substituted derivatives, through cytotoxicity tests on human HCC Bel7402 and human glioblastoma cell line $\mathrm{H} 4$, of which compounds (26) and (27) have excellent anti-proliferative activity against Bel7402 cancer cells $\left(\mathrm{IC}_{50}=0.02\right.$ and $\left.0.01 \mu \mathrm{M}\right)$. It is the first time to synthesize the derivative with $\mathrm{C}-\mathrm{C}$ bond at C-6 site and anticancer activity in vitro. It is believed that Michael receptor is not necessary for its antitumor activity, which provides a prospect for the optimization of celastrol derivatives of this series (Tang et al., 2015).

\section{Nano/Micro-Systems Encapsulated Celastrol}

Nano/micro-science generated nano/micro-size vehicle-based drug delivery systems have greatly facilitated the precise delivery of drugs to target cells or tissues. As a great excitement advancement in the area of targeted delivery, it possesses various advantages, such as enhancing target ability to target cells or tissues, overcoming drug resistance by intracellular delivery, and realizing sustained and controlled release (Bernabeu et al., 2017; Zhou et al., 2017). What's more, nano/micro-systems could also change the pharmacokinetics and toxicity profiles of parental drugs, enable drugs specific accumulation in the tumor tissue and release drugs at a synchronized rate, thereby maintaining synergistic drug ratios to achieve enhanced antitumor effects (Zhang, et al., 2017; Zhang J. et al., 2017; Xu and Liu 2019). Nowadays, different types of nano/micro-carriers have been employed to improve celastrol aqueous solubility, chemical stability, efficacy and safety, prolong celastrol biodistribution, reduce side effects of celastrol, such as liposomes, polymeric micelles, nanoparticles, micromulsions, inorganic and some other drug delivery system (Figure 8). The researches of several nano/micro-systems used to deliver celastrol and co-deliver celastrol and therapeutic drugs are listed in Tables 3, 4, respectively.

\section{Liposomes}

These vesicles are formed by a concentric lipid bilayer that entraps an aqueous core. The lipid membrane can be formed with phospholipids, lecithin and/or cholesterol and hydrophobic drugs can be incorporated in this bilayer, whereas hydrophilic drugs can be loaded in the aqueous core (Cagel et al., 2017). In one study (Song et al., 2011), celastrol-liposomes were prepared by the ethanol-injection method, and composed of phospholipid, cholesterol and Tween-80. The celastrol-loaded liposomes had improved effective permeability compared to the free drug in four intestinal segments. On the other hand, it also inhibited the tumor growth in C57BL/6 mice. Similarly, Huang et al. (2012) prepared liposomal celastrol using the thin-film dispersion method. In addition, a $4 \mathrm{mg} / \mathrm{kg}$ dose of liposomal celastrol had fewer severe side effects than free celastrol at the same dose. In this study, we found that the use of liposomes as a carrier of celastrol increased the bioavailability and reduced the side effects of celastrol. To overcome the shortcomings of celastrol and optimize its antitumor efficacy, galactose-modified PEGylated liposomes for targeted delivery of celastrol were prepared (Chen et al., 2020) (Figure 9). It could improve the water solubility of celastrol and exhibit high encapsulation efficiency, good stability in serum, and slow drug release profile. More importantly, it did not lead to serious weight loss and toxicity to normal organs.

On the other hand, a co-delivery system that sequentially releases its contents is an effective strategy to enhance anticancer efficacy. Researchers fabricated multicomponent-based liposomes loaded with sodium tanshinone IIA sulfonate (STS) and a small-sized microemulsion of celastrol, which shows 
TABLE 3 | The nanoparticles formulations of celastrol.

\begin{tabular}{|c|c|c|c|c|c|c|c|}
\hline $\begin{array}{l}\text { Nanocarrier } \\
\text { classification }\end{array}$ & $\begin{array}{l}\text { Nanocarrier } \\
\text { composition }\end{array}$ & $\begin{array}{l}\text { Encapsulation } \\
\text { method }\end{array}$ & Particle Size (nm) & Cell lines & Cancer type & Feature & Ref \\
\hline Carrier-free & - & $\begin{array}{l}\text { Physical } \\
\text { encapsulation }\end{array}$ & 125.7 & $\begin{array}{l}\text { MCF-7/ } \\
\text { MDR }\end{array}$ & Breast cancer & $\begin{array}{l}\text { Overcoming drug } \\
\text { resistance }\end{array}$ & $\begin{array}{l}\text { (Xiao et al., } \\
2018)\end{array}$ \\
\hline Exosomal & $\begin{array}{l}\text { Exosomes (isolated } \\
\text { from bovine raw milk) }\end{array}$ & $\begin{array}{l}\text { Physical } \\
\text { encapsulation }\end{array}$ & $106 \pm 9$ & $\begin{array}{l}\text { A549 and } \\
\text { H1299 }\end{array}$ & Lung cancer & $\begin{array}{l}\text { Enhance its efficacy and } \\
\text { reduce dose related toxicity }\end{array}$ & (Aqil et al., 2016) \\
\hline Liposomes & $\begin{array}{l}\text { Phospholipid, } \\
\text { cholesterol, tween-80 }\end{array}$ & $\begin{array}{l}\text { Physical } \\
\text { encapsulation }\end{array}$ & $89.6 \pm 7.3$ & Lewis cells & Lung carcinoma & $\begin{array}{l}\text { Improve effective } \\
\text { permeability; inhibit the } \\
\text { tumor growth }\end{array}$ & $\begin{array}{l}\text { (Song et al., } \\
\text { 2011) }\end{array}$ \\
\hline Liposomes & $\begin{array}{l}\text { SPC, sodium } \\
\text { deoxycholate }\end{array}$ & $\begin{array}{l}\text { Physical } \\
\text { encapsulation }\end{array}$ & $128.1 \pm 39.5$ & $\begin{array}{l}\text { U251, C6 } \\
\text { and SHG44 }\end{array}$ & Glioma & $\begin{array}{l}\text { Increase the bioavailability } \\
\text { and reduce the side effects }\end{array}$ & $\begin{array}{l}\text { (Huang et al., } \\
\text { 2012) }\end{array}$ \\
\hline Liposomes & $\begin{array}{l}\text { Gala-PEG-DSPE, SPC, } \\
\text { cholesterol }\end{array}$ & $\begin{array}{l}\text { Physical } \\
\text { encapsulation }\end{array}$ & $139.4 \pm 2.7$ & HepG2 & Liver cancer & $\begin{array}{l}\text { Improve the water solubility; } \\
\text { enhance the therapeutic } \\
\text { effect and reduce its } \\
\text { adverse effects }\end{array}$ & $\begin{array}{l}\text { (Chen et al., } \\
\text { 2020) }\end{array}$ \\
\hline $\begin{array}{l}\text { Polymeric } \\
\text { micelles }\end{array}$ & PEG-b-PCL & $\begin{array}{l}\text { Physical } \\
\text { encapsulation }\end{array}$ & 48 & SO-Rb 50 & Retinoblastoma & $\begin{array}{l}\text { Improve the hydrophilicity; } \\
\text { inhibit the growth and } \\
\text { induce apoptosis }\end{array}$ & $\begin{array}{l}(\llcorner i, W u \text {, et al., } \\
\text { 2012) }\end{array}$ \\
\hline $\begin{array}{l}\text { Polymeric } \\
\text { micelles }\end{array}$ & $\begin{array}{l}\text { CTTP-CSOSA, } \mathrm{NH}_{2-}^{-} \\
\text {PEG2000-NH }{ }_{2}\end{array}$ & $\begin{array}{l}\text { Physical } \\
\text { encapsulation }\end{array}$ & $63.5 \pm 18.0$ & MCF-7 & Breast cancer & $\begin{array}{l}\mathrm{pH} \text {-sensitive; mitochondrial } \\
\text { targeting }\end{array}$ & (Tan et al., 2018) \\
\hline $\begin{array}{l}\text { Polymeric } \\
\text { micelles }\end{array}$ & $\begin{array}{l}\text { TET-CSOSA, } \mathrm{NH}_{2^{-}} \\
\text {PEG2O00- } \mathrm{NH}_{2}\end{array}$ & $\begin{array}{l}\text { Physical } \\
\text { encapsulation }\end{array}$ & $82.5 \pm 3.6$ & $4 \mathrm{~T} 1$ & Breast cancer & $\begin{array}{l}\text { avb3- targeted; improve } \\
\text { antitumor metastasis } \\
\text { therapy }\end{array}$ & $\begin{array}{l}\text { (Zhao et al., } \\
\text { 2018) }\end{array}$ \\
\hline $\begin{array}{l}\text { Phospholipid } \\
\text { complex }\end{array}$ & SPC, PEG 400 & $\begin{array}{l}\text { Physical } \\
\text { encapsulation }\end{array}$ & $178.4 \pm 7.07$ & - & - & $\begin{array}{l}\text { Improve solubility and oral } \\
\text { bioavailability }\end{array}$ & $\begin{array}{l}\text { (Freag, Saleh, } \\
\text { and Abdallah } \\
\text { 2018b) }\end{array}$ \\
\hline $\begin{array}{l}\text { Phospholipid } \\
\text { complex }\end{array}$ & $\begin{array}{l}\text { CS, HPMC, protamine, } \\
\text { SPC }\end{array}$ & $\begin{array}{l}\text { Physical } \\
\text { encapsulation }\end{array}$ & $180.4 \pm 6.16$ & - & - & $\begin{array}{l}\text { Improve the absorption; } \\
\text { higher bioavailability }\end{array}$ & $\begin{array}{l}\text { (Freag, Saleh, } \\
\text { and Abdallah } \\
\text { 2018a) }\end{array}$ \\
\hline Nanoparticles & PCL, tween 80 & $\begin{array}{l}\text { Physical } \\
\text { encapsulation }\end{array}$ & 75.4 & LNCaP & Prostatic cancer & $\begin{array}{l}\text { Improve the } \\
\text { pharmacokinetics and } \\
\text { biodistribution }\end{array}$ & (Yin et al., 2017) \\
\hline Nanoparticles & $\begin{array}{l}\text { SPC, TPGS, F68, IPM, } \\
\text { glyceryl behenate }\end{array}$ & $\begin{array}{l}\text { Physical } \\
\text { encapsulation }\end{array}$ & $90.2 \pm 9.7$ & B16BL6 & Melanoma & $\begin{array}{l}\text { Enhance the percutaneous } \\
\text { penetration and } \\
\text { antimelanoma efficacy }\end{array}$ & $\begin{array}{l}\text { (Chen et al., } \\
\text { 2012) }\end{array}$ \\
\hline Nanoparticles & $\begin{array}{l}\text { CPP, precirol ATO-5, } \\
\text { 1944CS, F68, TPGS, } \\
\text { soybean lecithin }\end{array}$ & $\begin{array}{l}\text { Physical } \\
\text { encapsulation }\end{array}$ & $126.7 \pm 9.2$ & $\begin{array}{l}\text { PC-3 and } \\
\text { RM-1 }\end{array}$ & Prostate cancer & $\begin{array}{l}\text { Improve the hydrophilicity; } \\
\text { enhance antitumor activity } \\
\text { in vitro and in vivo; No } \\
\text { signifcant adverse effects }\end{array}$ & $\begin{array}{l}\text { (Yuan et al., } \\
\text { 2013) }\end{array}$ \\
\hline $\begin{array}{l}\text { Lipid } \\
\text { nanospheres }\end{array}$ & $\begin{array}{l}\text { Lecithin, sodium oleate, } \\
\text { soybean oil }\end{array}$ & $\begin{array}{l}\text { Physical } \\
\text { encapsulation }\end{array}$ & 150 & - & - & $\begin{array}{l}\text { Enhance the oral } \\
\text { bioavailability }\end{array}$ & $\begin{array}{l}\text { (Zhang et al., } \\
\text { 2014) }\end{array}$ \\
\hline Nanoparticles & PCL, F-127 & $\begin{array}{l}\text { Physical } \\
\text { encapsulation }\end{array}$ & $175.5 \pm 4.7$ & $\begin{array}{l}\text { LNCaP, } \\
\text { DU-145 and } \\
\text { PC3 }\end{array}$ & Prostate cancer & $\begin{array}{l}\text { Exhibit remarkable } \\
\text { antiproliferative activities }\end{array}$ & $\begin{array}{l}\text { (Sanna et al., } \\
\text { 2015) }\end{array}$ \\
\hline Nanoparticles & $\begin{array}{l}\text { PEG-PLGA, neutrophil } \\
\text { membrane }\end{array}$ & $\begin{array}{l}\text { Physical } \\
\text { encapsulation }\end{array}$ & $167.4 \pm 2.6$ & Panc02 & $\begin{array}{l}\text { Pancreatic } \\
\text { carcinoma }\end{array}$ & $\begin{array}{l}\text { Enhance tumor inhibition } \\
\text { which significantly } \\
\text { prolonging the survival of } \\
\text { tumor bearing mice and } \\
\text { minimizing liver metastases }\end{array}$ & $\begin{array}{l}\text { (Cao et al., } \\
\text { 2019) }\end{array}$ \\
\hline Nanoparticles & SF & $\begin{array}{l}\text { Physical } \\
\text { encapsulation }\end{array}$ & $292.7 \pm 28.1$ & - & $\begin{array}{l}\text { Pancreatic ductal } \\
\text { adenocarcinoma }\end{array}$ & $\begin{array}{l}\text { Improve pharmacokinetic } \\
\text { properties }\end{array}$ & $\begin{array}{l}\text { (Onyeabor et al., } \\
\text { 2019) }\end{array}$ \\
\hline Nanoparticles & $\begin{array}{l}\text { PEG-PLGA, neutrophil } \\
\text { membranes }\end{array}$ & $\begin{array}{l}\text { Physical } \\
\text { encapsulation }\end{array}$ & - & $\mathrm{B} 16 \mathrm{~F} 10$ & Melanoma & $\begin{array}{l}\text { Neutrophils-targeted; } \\
\text { prolong blood circulation; } \\
\text { improve antitumor efficacy }\end{array}$ & $\begin{array}{l}\text { (Zhou et al., } \\
\text { 2019) }\end{array}$ \\
\hline $\begin{array}{l}\text { Inorganic } \\
\text { systems }\end{array}$ & Glucose, PEI, MSN & $\begin{array}{l}\text { Physical } \\
\text { encapsulation }\end{array}$ & 615 & $\begin{array}{l}\text { HeLa and } \\
\text { A549 }\end{array}$ & $\begin{array}{l}\text { Cervical cancer; } \\
\text { Lung cancer }\end{array}$ & $\begin{array}{l}\text { Glucose-targeted; enhance } \\
\text { anti-cancer activity; Did not } \\
\text { induce any toxicity }\end{array}$ & $\begin{array}{l}\text { (Niemela et al., } \\
\text { 2015) }\end{array}$ \\
\hline $\begin{array}{l}\text { Inorganic } \\
\text { systems }\end{array}$ & $\mathrm{TiO}_{2}$ & $\begin{array}{l}\text { Physical } \\
\text { encapsulation }\end{array}$ & $\begin{array}{l}\text { width about } 80 \mathrm{~nm} \\
\text { and length range } \\
\text { from } 200 \text { to } \\
5,000 \mathrm{~nm}\end{array}$ & HepG2 & Liver cancer & $\begin{array}{l}\text { Enhance the cytotoxicity of } \\
\text { celastrol; reduce the side- } \\
\text { effect }\end{array}$ & (Li et al., 2011) \\
\hline Dendrimers & G5 PAMAM, PEG & $\begin{array}{l}\text { Chemical } \\
\text { conjugation }\end{array}$ & 40 & SW620 & Colorectal cancer & $\begin{array}{l}\text { Aptamers-targeted; reduce } \\
\text { the side-effect }\end{array}$ & (Ge et al., 2020) \\
\hline
\end{tabular}

SPC, soybean phosphatidylcholine; gala-PEG-DSPE, galactose-modified 1,2-distearoyl-sn-glycero-3-phosphoethanolamine-poly(ethylene glycol); $P C L$, poly-( $\varepsilon$-caprolactone); PEG-b-PCL, poly(ethylene glycol)-block-poly(E-caprolactone); CTPP, (4-Carboxybutyl) triphenylphosphonium bromide; SA, stearic acid; CSO, chitosan oligosaccharide; CS, laminated chitosan; HPMC, hydroxypropyl methylcellulose; TPGS, d- $\alpha$-tocopherol polyethylene glycol succinate 1000; IPM, isopropyl myristate; CPP, cell-penetrating peptides; $1944 C S$, labrafil $\mathbb{R}$ M 1944CS; F68, Pluronic F68; SF, silk fibroin; PEI, poly(ethylene imine); MSNs, mesoporous silica nanoparticles; $\mathrm{TiO}_{2}$, titanium dioxide; PAMAM, hydroxyl terminus poly(amidoamine). 
TABLE 4 | The anticancer nano/micro-systems for celastrol and therapeutic drugs co-delivery.

\begin{tabular}{|c|c|c|c|c|c|c|c|c|}
\hline $\begin{array}{l}\text { Nanocarrier } \\
\text { classification }\end{array}$ & $\begin{array}{l}\text { Nanocarrier } \\
\text { composition }\end{array}$ & $\begin{array}{c}\text { Combination } \\
\text { drug }\end{array}$ & $\begin{array}{l}\text { Encapsulation } \\
\text { method }\end{array}$ & $\begin{array}{l}\text { Particle } \\
\text { Size } \\
(\mathbf{n m})\end{array}$ & $\begin{array}{l}\text { Cell } \\
\text { lines }\end{array}$ & $\begin{array}{l}\text { Cancer } \\
\text { type }\end{array}$ & Feature & Ref \\
\hline Liposomes & $\begin{array}{l}\text { Coix oil, RH40, PEG400, } \\
\text { SPC, cholesterol }\end{array}$ & STS & $\begin{array}{l}\text { Physical } \\
\text { encapsulation }\end{array}$ & $94.8 \pm 3.6$ & MCF-7 & Breast cancer & $\begin{array}{l}\text { Sequential drug release; Display } \\
\text { diminished systemic toxicity }\end{array}$ & $\begin{array}{l}\text { (Qu et al., } \\
\text { 2018) }\end{array}$ \\
\hline Liposomes & $\begin{array}{l}\text { DPPC, SPC, GNR-DSPE- } \\
\text { PEG, cholesterol }\end{array}$ & STS & $\begin{array}{l}\text { Physical } \\
\text { encapsulation }\end{array}$ & $122.6 \pm 0.6$ & MCF-7 & Breast cancer & $\begin{array}{l}\text { Photothermal-triggered; } \\
\text { sequential drug release; display } \\
\text { diminished systemic toxicity }\end{array}$ & $\begin{array}{l}\text { (Qin et al., } \\
\text { 2020) }\end{array}$ \\
\hline Polymeric micelles & Celastrol-PEG-G Rh2 & $\begin{array}{l}\text { Ginsenoside } \\
\text { Rh2 }\end{array}$ & $\begin{array}{l}\text { Chemical } \\
\text { conjugation }\end{array}$ & $121.53 \pm 2.35$ & A549 & Lung cancer & $\begin{array}{l}\text { pH-sensitive; precisely release } \\
\text { anticancer drugs and improve } \\
\text { synergistic anti-lung cancer effect }\end{array}$ & $\begin{array}{l}(\text { Li et al., } \\
2017)\end{array}$ \\
\hline Nanoparticles & AEAA-PEG-BAP & Mitoxantrone & $\begin{array}{l}\text { Physical } \\
\text { encapsulation }\end{array}$ & $112 \pm 6$ & BPD6 and D4M & Desmoplastic melanoma & $\begin{array}{l}\mathrm{pH} \text {-sensitive and reduction- } \\
\text { sensitive; reduce drug exposure } \\
\text { and side-effects }\end{array}$ & $\begin{array}{l}\text { (Liu et al., } \\
\text { 2018) }\end{array}$ \\
\hline Nanoparticles & SF & Triptolide & $\begin{array}{l}\text { Physical } \\
\text { encapsulation }\end{array}$ & $\begin{array}{l}\text { TP: } 166.4 \pm 4.6 \\
\text { CL: } 170.4 \pm 2.3\end{array}$ & $\begin{array}{l}\text { MIA PaCa-2 and } \\
\text { PANC-1 }\end{array}$ & Pancreatic cancer & Increase the growth inhibition & $\begin{array}{l}\text { (Ding et al., } \\
\text { 2017) }\end{array}$ \\
\hline Nanoparticles & HA, BSA, soybean oil & MT & $\begin{array}{l}\text { Physical } \\
\text { encapsulation }\end{array}$ & $205.7 \pm 5.4$ & Panc02 & Pancreatic cancer & $\begin{array}{l}\text { CD44 targeted; enhance tumor } \\
\text { inhibition; alleviate the adverse } \\
\text { effect and improve the safety }\end{array}$ & $\begin{array}{l}\text { (Hu et al., } \\
\text { 2019) }\end{array}$ \\
\hline Microemulsions & $\begin{array}{l}\text { DSPE-PEG-Tf, PEG 400, } \\
1944 C S, \text { HS15 }\end{array}$ & $\beta$-elemene & $\begin{array}{l}\text { Physical } \\
\text { encapsulation }\end{array}$ & $69.2 \pm 3.3$ & A549 & Lung cancer & $\begin{array}{l}\text { TF-targeted; exhibit enhanced } \\
\text { antitumour activity; did not cause } \\
\text { the obvious systemic toxicity }\end{array}$ & $\begin{array}{l}\text { (Zhang Q. } \\
\text { et al., 2019) }\end{array}$ \\
\hline Microemulsions & TF, PEG 400 & Coix seed oil & $\begin{array}{l}\text { Physical } \\
\text { encapsulation }\end{array}$ & 27.7 & HeLa & Cervical cancer & $\begin{array}{l}\text { TF-targeted, enhance } \\
\text { tumortargeting; facilitate deep } \\
\text { penetration of drugs; enhance } \\
\text { antitumor efficacy with little toxicity }\end{array}$ & $\begin{array}{l}\text { (Guo et al., } \\
\text { 2019) }\end{array}$ \\
\hline $\begin{array}{l}\text { Composite } \\
\text { nanoparticles (MSN + } \\
\text { Lipid) }\end{array}$ & $\begin{array}{l}\text { MSN, cholesterol B, NBD-PC, } \\
\text { DPPC, DSPE-PEG2000 }\end{array}$ & Axitinib & $\begin{array}{l}\text { Physical } \\
\text { encapsulation }\end{array}$ & 120 & $\begin{array}{l}\text { SCC-7, BT-474 } \\
\text { and SH-SY5Y }\end{array}$ & $\begin{array}{l}\text { Squamous carcinoma, breast } \\
\text { cancer and neuroblastoma }\end{array}$ & Enhance antitumor efficacy & $\begin{array}{l}\text { (Choi et al., } \\
\text { 2016) }\end{array}$ \\
\hline
\end{tabular}

SPC, soybean phosphatidylcholine; STS, sodium tanshinone IIA sulfonate; DPPC, 1,2-Dipalmitoyl-sn-glycero-3-phosphocholine; GNR-DSPE-PEG, gold nanorods-1,2-distearoyl-sn-glycero-3-phosphoethanolamineN-[amino (polyethylene glycol); PEG, poly(ethylene glycol); G Rh2, ginsenoside Rh2; BAP, bis(acryloyloxymethyl)propionate; AEAA, aminoethylanisamide; SF, silk fibroin; HA, hyaluronic acid; BSA, bovine serum albumin; MT, 1-methyltryptophan; DSPE-PEG-Tf, transferrinmodified 1,2-distearoyl-sn-glycero-3-phosphoethanolamineN-[amino (polyethylene glycol); 1944CS, labrafil囚 M 1944CS; HS15, kolliphorß HS15; TF, transferrin; MSNs, mesoporous silica nanoparticles; NBD-PC, 1-palmitoyl-2(6-[(7-nitro-2-1,3-benzoxa diazol-4-yl) amino]hexanoyl)-sn-glycero-3-phosphocholine. 


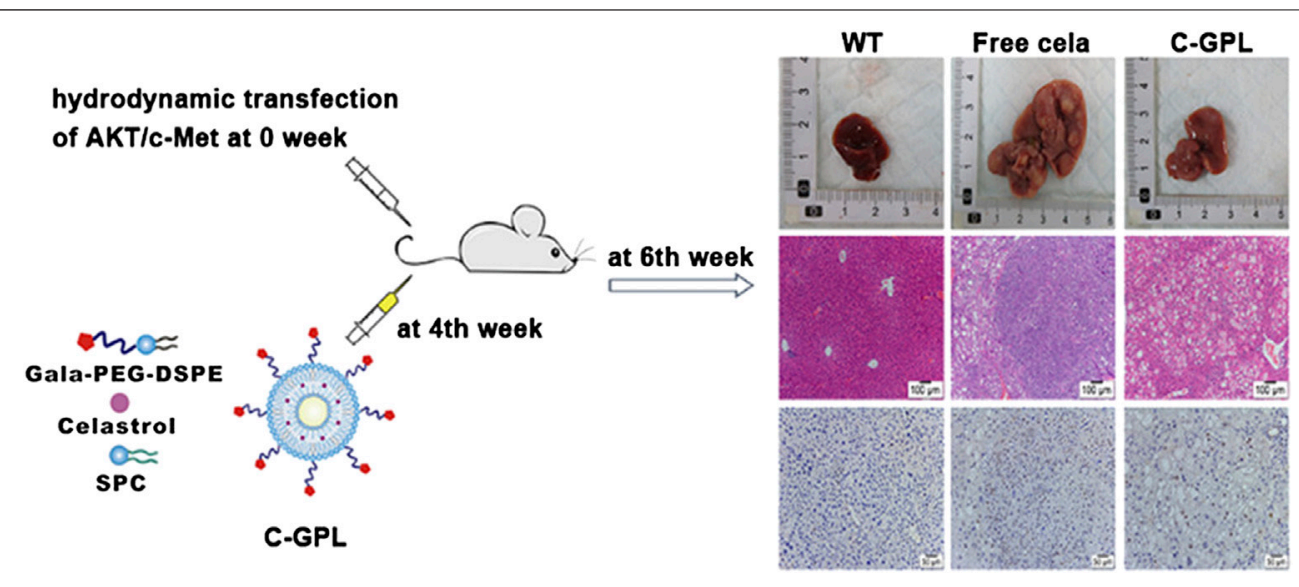

FIGURE 9 | Liver-targeting liposomes were developed using galactose-modified 1,2-distearoyl-sn-glycero-3-phosphoethanolamine-poly(ethylene glycol) (galaPEG-DSPE), natural soybean phosphatidylcholine (SPC), and cholesterol for delivery of celastrol to hepatic tissues (C-GPL). Reprinted with permission (Chen et al., 2020).

synergistic anti-breast cancer activity through the initial release of STS for modulation of the tumor microenvironment, and subsequent release of celastrol for eradication of tumor tissues (Qu et al., 2018). Furthermore, it displayed diminished systemic toxicity compared to celastrol used alone. Thus offers a novel strategy for combination anticancer treatment and holds promising potential not only for breast cancer treatment, but also for the treatment of other solid tumors. Similarly, Qin et al. fabricate a gold nanorod-anchored thermo-sensitive liposomal complex co-loaded with STS and celastrol (G-T/C-L), which can sequentially release STS and celastrol upon NIR irradiation at $808 \mathrm{~nm}$. When G-T/C-L reaches the sites, NIR illumination produces mild heat $\left(\sim 43^{\circ} \mathrm{C}\right)$ and thereby triggers a rapid release of STS in the initial stage, decreasing the level of tumoral blood vessels, collagen, cancerassociated fibroblasts, and Th2 type cytokines. In the subsequent stage, celastrol was unloaded to exert anticancer effect under an activated tumor microenvironment. Due to the treatment of G-T/C-L with NIR illumination shows a significant improvement in anticancer efficacy both in vitro and in vivo but without conventional photothermal therapy-associated side effects, it enriches the application with combinational STS and celastrol in anti-breast cancer therapy.

\section{Polymeric Micelles}

Li Z. et al. (2012), Li Y. et al., (2012) found that PEG-b-PCL micelles had promising potential to improve the hydrophilicity of celastrol and extend its release. Therefore, celastrol-loaded poly(ethylene glycol)-block-poly( $\varepsilon$-caprolactone) (PEG-b-PCL) nanopolymeric micelles were prepared to inhibit the growth of retinoblastoma and induce apoptosis in retinoblastoma cells in mice. Active targeting therapy-mediated drug delivery system has been shown to reduce systemic toxicity and achieve targeted synergistic effects (Mo et al., 2014; Wang et al., 2014). A celastrol loaded glucolipid-like conjugates (CSOSA/Cela) with avb3-ligand tetraiodothyroacetic acid (TET) modification (TET-CSOSA/ Cela) were established to preparation of polymer micelles. In this study, it exploited a delivery system for improved antitumor metastasis therapy, which not only targeted breast tumor but also lung metastasis by means of avb3 receptor-mediated interaction. The results of $4 \mathrm{~T} 1$ metastasis inhibition showed that TET-CSOSA/Cela could suppress breast tumor invasion and lung metastasis growth through inhibition of $\mathrm{NF}_{-\kappa} \mathrm{B}$ signaling pathway (Figure 10) (Zhao et al., 2018). In another study, the (4-Carboxybutyl) triphenylphosphonium bromide (CTTP)-CSOSA/Cela micelles were developed for mitochondrial targeting and alkaline $\mathrm{pH}$-responsive drug release to treat cancer. Importantly, CTPP-CSOSA/Cela micelles could selectively accumulate in tumor cell mitochondria, and realize fast drug release by responsing to mitochondrial alkaline $\mathrm{pH}$ environment, resulting in the significant apoptosis of tumor cells. Furthermore, CTPP modified CSOSA gave rise to its accumulation in tumor tissues (Tan et al., 2018). Li et al. (2017) report the development of a polymeric material with a three-section structure, "hydrophobic-hydrophilic-hydrophobic," through the covalent conjugation of celastrol and ginsenoside Rh2 onto both ends of PEG segments via ester linkages. It could rapidly release drugs under acidic and enzymatic conditions, but slowly released in normal physiological environments. Therefore, it is a promising vector for precisely releasing anticancer drugs within the tumor cells, and thereby exerts an improved synergistic anti-lung cancer effect.

\section{Nanoparticles}

Oral delivery of celastrol remains challenging because of limited water-solubility and/or poor permeability. Nanostructured lipid carriers (NLCs) are attractive materials for topical drug delivery. The surface charge of NLCs has a great influence on the skin permeation and pharmacodynamics of celastrol. Cationic celastrol-loaded NLCs could enhance the percutaneous penetration and antimelanoma efficacy of celastrol and offer several advantages over celastrol alone (Chen et al., 2012). Similarly, aimed to enhance the oral bioavailability of celastrol, 


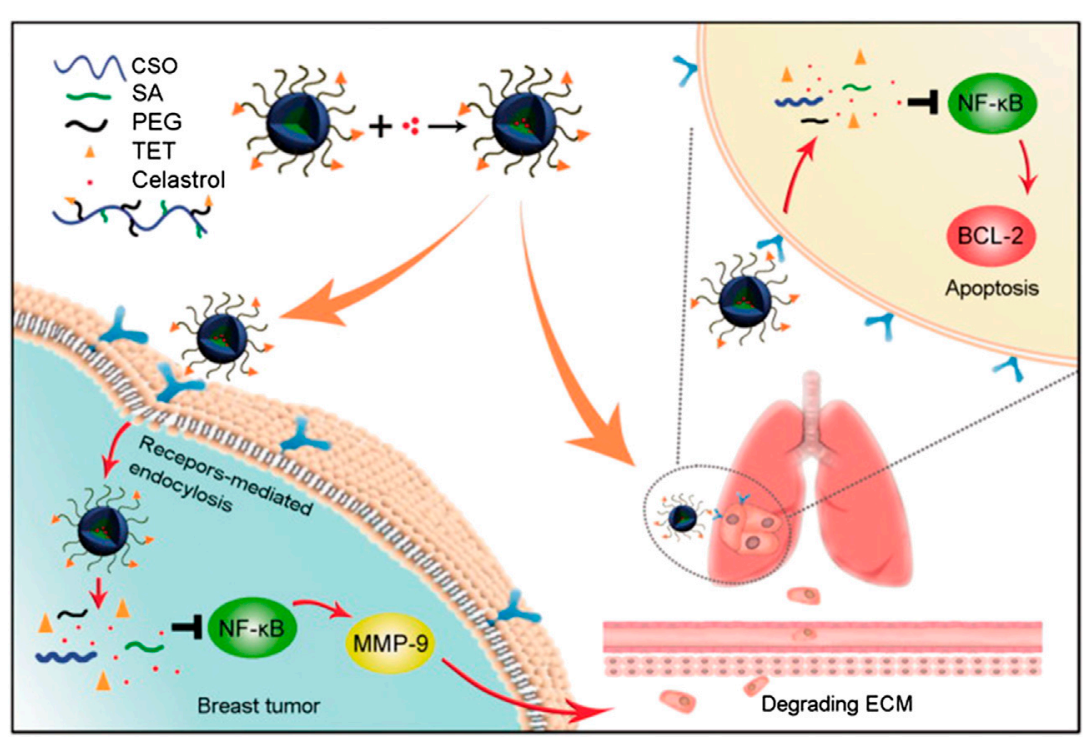

FIGURE 10 | The schematic diagram of simultaneous targeting therapy for lung metastasis and breast tumor. Reprinted with permission (Zhao et al., 2018).

celastrol-loaded lipid nanospheres (LNs) were prepared by rapid dispersion of an ethanol mixture of celastrol, lecithin, sodium oleate, and soybean oil into water. The pharmacokinetic results showed that LNs significantly enhanced the oral bioavailability of celastrol with a relative bioavailability of $224.88 \%$ (celastrol suspensions was used as a reference). The mechanistic studies demonstrated that improved intestinal permeability and postenterocyte lymphatic transport were mainly responsible for the enhanced oral absorption (Zhang et al., 2014).

Sanna and colleagues (Sanna et al., 2015) indicated that nanoencapsulation would represent a powerful strategy to overcome these issues of celastrol. In their study, they developed novel celastrol-loaded PCL nanoparticles, and the nanoparticles significantly increased cytotoxicity at lower/ medium dose $(0.5$ and $1.0 \mu \mathrm{M})$ on DU145 and PC3 cell lines with respect to free celastrol. Besides, to improve the hydrophilicity of celastrol, Chen and co-workers developed cell-penetrating peptides (CPP)-coated celastrol-loaded NLCs. It noticeably enhanced antitumor activity in vitro and in vivo with no significant adverse effects (Yuan et al., 2013). Additionally, due to the application of celastrol-loaded silk fibroin (SF) nanoparticles, the pharmacokinetic profile was improved with celastrol-loaded SF nanoparticles compared to pure celastrol-which was observed following IV administration. The initial concentration of celastrol nanoparticles was four times higher than that of celastrol in solution and celastrol-SF nanoparticles demonstrated longer mean residence time (Onyeabor et al., 2019). In another study, researchers aimed to develop polymeric nanoparticles combined with the reticuloendothelial system (RES) saturation to improve the in vivo distribution and antitumor activity of celastrol. The pharmacokinetic studies revealed that celastrol-nanoparticles had the advantage in bettering the pharmacokinetic properties of celastrol over the solution formulation. However, the ameliorative effect on pharmacokinetics was more significant in the case of RES saturation (Yin et al., 2017).

Recently, the application of neutrophils as therapeutic vehicles in cancer therapy has gradually been recognized (Xue et al., 2017). Meanwhile, Kang et al. (2017), Li R. et al. (2018) highlighted the use of activated neutrophil membrane-coated nanoparticles targeting to circulating tumor cells in the treatment of metastatic breast tumor. Hence, Cao et al. (2019) fabricated naïve neutrophil membrane-coated PEG-PLGA nanoparticles (NNPs) to achieve pancreas-specific delivery of celastrol by overcoming the blood-pancreas barrier. The result showed NNPs selective accumulations at the tumor site following systemic administration as compared to nanoparticles without neutrophil membrane coating. In both orthotopic and ectopic tumor models, celastrol-loaded NNPs demonstrated greatly enhanced tumor inhibition which significantly prolonged the survival of tumor bearing mice and minimizing liver metastases. Similarly, celastrol-loaded PEG-PLGA nanoparticles coated with neutrophil membranes displayed significantly enhanced cytotoxicity and apoptosis rate in a murine melanoma cell line B16F10 compared to celastrolloaded PEG-PLGA nanoparticles (Zhou et al., 2019).

Combination therapy is the routine strategy of cancer chemotherapy with significant advantages including lower treatment failure rate and slower development of drug resistance. Ding and coworkers (Ding et al., 2017) developed and characterized triptolide-loaded SF nanoparticles and celastrol-loaded SF nanoparticles separately, which not only overcame the pitfall of hydrophobicity, but also facilitated triptolide and celastrol passively accumulating in cancerous tissues based on the Enhanced Permeability and Retention effect as well as definition of optimal dose and schedule of administration. Further, hierarchical assembly of hyaluronic acid coated albumin nanoparticles were utilized to co-deliver 


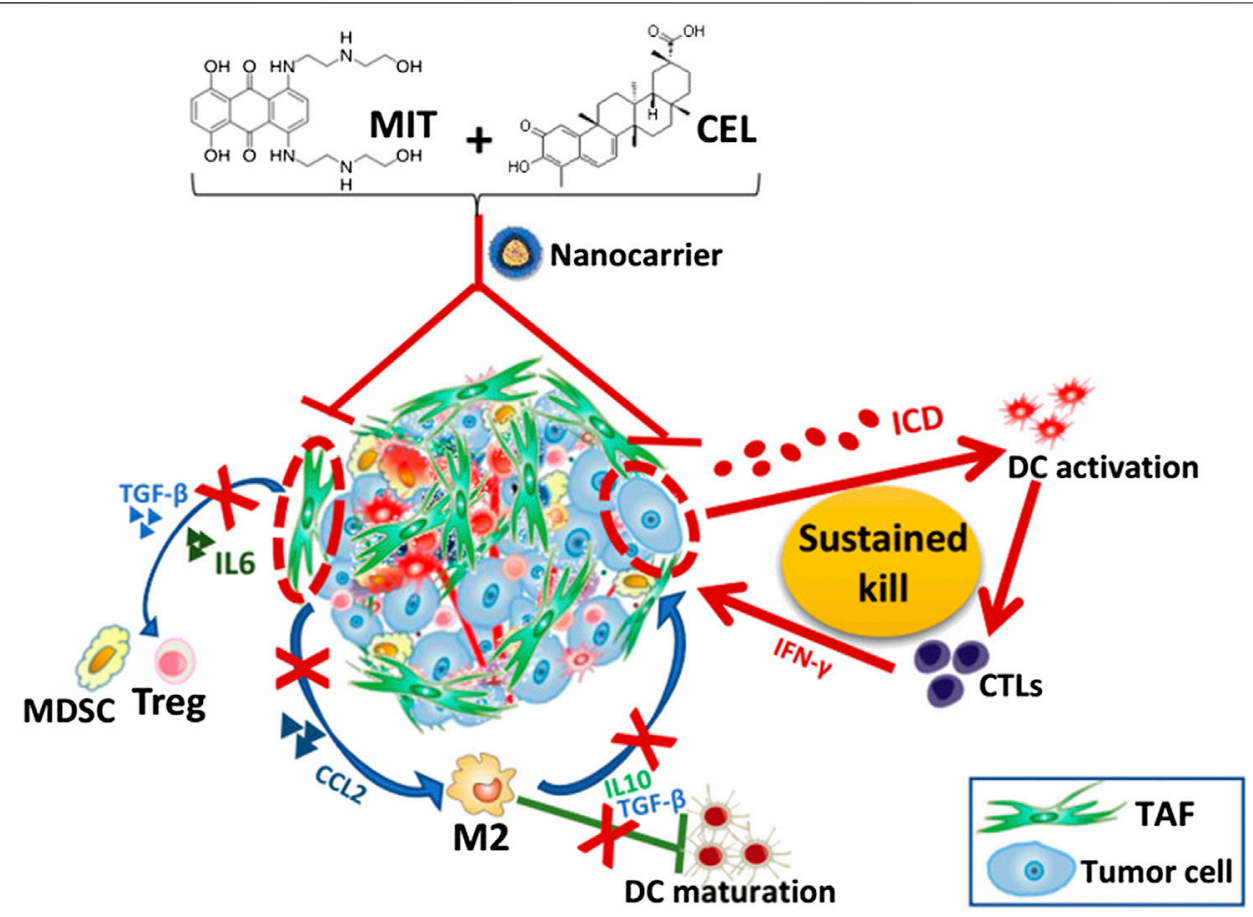

FIGURE 11 | Figure legend depicting nanocarrier-mediated chemo-immuno therapy by co-delivering MIT and CEL. MIT, mitoxantrone; CEL, celastrol; TAF, tumor associated fibroblast; ICD, immunogenic cell death; DC, dendritic cell; CTL, cytotoxic T lymphocyte; MDSC, myeloid-derived suppressor cell; Treg, regulatory T cell; M2, M2 macrophage. Reprinted with permission (Liu Q. et al., 2018).

celastrol and 1-methyltryptophan (MT). The nanoparticles with a unique hollow structure selectively accumulated in both the xenograft pancreatic tumor and the orthotopic pancreatic tumor site following systemic administration possibly via sizereduction effect, and the CD44 mediated accumulation and internalization. Thus significantly enhanced tumor inhibition and alleviated the adverse effect and improved the safety of using celastrol in vivo (Hu et al., 2019). Another study showed that developed an innovative chemo-immuno strategy based on targeted delivery of mitoxantrone and celastrol, two potent medicines screened and selected with the best anti-cancer and anti-fibrosis potentials. The combination targets tumorassociated fibroblasts to reduce the desmoplasia of the tumor. The chemo-immuno therapy significantly remodeled immunesuppressive tumor microenvironment, as well as triggered a robust immune memory response. Since only low doses of both drugs were used, the treatment was without any toxicity to the host (Liu Q. et al., 2018) (Figure 11).

\section{Microemulsions}

Microemulsions result from the dispersion of two immiscible liquids, typically water and oil, and are stabilized using an appropriate surfactant (Singh et al., 2017). It has been reported that transferrin-functionalized microemulsions coloaded with coix seed oil and celastrol (Tf-CT-MEs) for the treatment of cervical cancer, which promoted accumulation at the tumor site, improved permeability in tumor tissues, retarded tumor growth, inhibited tumor cell proliferation, promoted tumor cell apoptosis, enhanced antiangiogenesis, and downregulated the concentration of protumoral cytokines in serum. Meanwhile, Tf-CTMEs showed little toxicity against normal noncancerous organs (Guo et al., 2019). Using tumortargeted and combinational microemulsions, this study provides a potential strategy for improving anticervical cancer therapy. In another study, co-delivery of $\beta$-elemene and celastrol using Tffunctionalized microemulsion (Tf-EC-MEs) exhibited enhanced antitumor activity compared to all other treatments. More importantly, Tf-EC-MEs did not cause the obvious systemic toxicity commonly found with mono-celastrol treatment (Zhang Q. et al., 2019). Therefore, using tumor-targeted and combinational microemulsions provides a potential strategy for improving anti-cancer therapy of celastrol.

\section{Inorganic Nano-Systems}

Li et al. (2011) introduced biocompatible titanium dioxide $\left(\mathrm{TiO}_{2}\right)$ nanofibers into the research of celastrol, And after the $\mathrm{TiO}_{2}$ nanofibers were introduced into the system of celastrol, the cooperation effect showed that the nanocomposites between $\mathrm{TiO}_{2}$ nanofibers and celastrol could enhance the cytotoxicity of celastrol for HepG2 cells and cut down the drug consumption so as to reduce the side-effect of celastrol. In addition, Niemelä and colleagues (Niemela et al., 2015) utilized glucose as an affinity ligand decorated on mesoporous silica nanoparticles (MSNs), with the aim of delivering these celastrol-loaded MSNs with high specificity to cancer cells and inducing minimal off-target effects in healthy cells. MSNs were 
thus functionalized with sugar moieties by two different routes, either by conjugation directly to the MSN surface or mediated by a hyperbranched poly (ethylene imine, PEI) layer; the latter to increase the cellular uptake by providing an overall positive surface charge as well as to increase the reaction sites for sugar conjugation. The particles themselves did not induce any toxicity, and normal cells displayed minimal off-target effects. During the study carried out by Choi and teams (Choi et al., 2016) the researchers prepared axitinib/celastrol-loaded combination nanoparticles (ACML) with celastrol loaded in the MSN and axitinib in PEGylated lipidic bilayers. It demonstrated that the administration of ACML effectively inhibited angiogenesis and mitochondrial function and was efficiently internalized in the SCC-7, BT-474, and SH-SY5Y cell lines.

\section{Other Nano-Systems}

Xiao et al. (2018) designed and synthesized a carrier-free and biocompatible nanomedicine based on a simple and green selfassembly method, for synergistic combination chemotherapy of celastrol and doxorubicin to overcome MDR and promote chemotherapeutic effect. Spherical nanoparticles can improve the water-solubility of celastrol, reduce the dosage of doxorubicin, and therefore obviously enhance cellular drug accumulation via activating Heat shock factor 1 (HSF-1) and inhibiting NF- $\mathrm{kB}$ to depress $\mathrm{P}$-gp expression, which result in apoptosis and autophagy of doxorubicin resistant cells through ROS/JNK signaling pathway. Aqil et al. (2016) isolated exosomes from bovine raw milk, and used physical encapsulation to prepare celastrol-loaded exosomes. The data have shown that celastrol-loaded exosomes enhance free celastrol efficacy and reduce dose-related toxicity in lung cancer. Exosomes loaded with celastrol exhibited enhanced anti-tumor efficacy as compared to free celastrol against lung cancer cell xenograft. Besides, celastrol did not exhibit any gross or systemic toxicity in wild-type C57BL6 mice as determined by hematological and liver and kidney function test. Freag and coworkers developed self-assembled phytosomal nanocarriers for improving celastrol solubility and oral bioavailability. Celastrol-phospholipid complex (CST-PHY) was prepared using simple solvent evaporation technique. The pharmacokinetic studies in rabbits revealed significant improvement in CST-PHY oral bioavailability compared with crude celastrol evidenced by 4 -fold increase in $\mathrm{AUC}_{0-8}$ and 5-fold increase in $\mathrm{C}_{\max }$ of CST-PHY compared with crude celastrol (Freag et al., 2018b). The teams also reported (Freag et al., 2018a) to surmount the celastrol's pharmaceutical obstacles and improve its bioavailability, protamine-coated phytosomal nanocarriers were prepared. And, the nanocarriers was loaded into laminated chitosan (CS): hydroxypropyl methylcellulose (HPMC) composite sponges as flexible and soft mucoadhesive dosage form to control drug release kinetics and permeation via buccal mucosa. Conclusively, mucoadhesive CS-HPMC sponges loaded with a novel mucopenetrating nanocarrier could significantly improve the absorption of celastrol via buccal mucosa which would be of prime importance for its clinical utility. In another team (Ge et al., 2020), their work aimed at developing bioconjugates composed of EpCAM aptamer, PEG and dendrimers for specifically delivering celastrol into EpCAM-abundant tumors to improve the antitumor efficacy and mitigate the toxicity. The results exhibited much reduced local and systemic toxicity both in xenograft mice and zebrafish models. Thus these data indicate that the integrated strategydesigned dendrimer delivery system represents a promising application of celastrol in targeted cancer treatment with great biosafety and specificity.

\section{CURRENT PERSPECTIVES AND CHALLENGES \\ Taking Advantage of Combination Chemotherapy}

Effective combination therapy for anticancer treatment requires dealing with an investigation of multiple hurdles. Moreover, prior to selecting the combination of therapeutic agents, a deep analysis of cancer pathways involved, feedback loops, alternative mechanisms, genetic profile and existed treatment obstacle should be considered thoroughly. Due to the important role of celastrol in the EMT, the design of combination strategies can be based on this to carry out more research. Moreover, tumor microenvironment favors tumor cells to promote their growth and metastasis such as migration, invasion, and angiogenesis. Lee et al. introduce celastrol, as an inhibitor of NLRP3 infammasome, to reduce the potency of macrophages to stimulate migration and invasion of melanoma cells, which provide a novel anti-cancer strategy to modulate tumor microenvironment by suppressing NLRP3 infammasome and consequently reducing IL-1 $\beta$ production (Lee et al., 2019). Therefore, combining drug strategy based on tumor microenvironment may achieve twice the result with half the effort. More systematic and mechanistic studies are useful to identify optimal drug synergism, and intensification of research on combination regimes with other therapies in clinical use could facilitate translation of celastrol formulations (Baran et al., 2014; Mahbub et al., 2015). On the other hand, in addition to conventional chemotherapy, we need as many combinations of modern therapies as possible, such as gene therapy, immunotherapy, photothermal or photodynamic therapy, etc. (Liu Y. et al., 2018; Haasteren et al., 2018; Sanmamed and Chen, 2018; Sun et al., 2019).

\section{Taking Advantage of Analogs of Celastrol}

Although celastrol has already been proved to have significant anticancer activity through functional phenotypic screening in vitro and in vivo, its precise molecular targets that responsible for the potent biological activity have not yet been fully identified (Kashyap et al., 2018). Hence, it is important to further design and synthesis of new bioactive probes of celastrol to identify unexplored molecular targets and map the integral signaling networks that responsible for its effects and toxicity.

The reported modifications are limited on C-2, C-3 of A-ring, C-6 of B-ring and C-20 of E-ring, while decoration on other sites of this molecule is still underdeveloped. Therefore, despite it is of great challenging, a part of the future work should be devoted to 
investigating the structure-activity relationship caused by modification on other sites of celastrol.

Biotransformation or biosynthesis is becoming an increasingly powerful tool for the synthesis or structure modification of complex natural products (Jobby et al., 2018; Khojasteh et al., 2018). Therefore, it is meaningful to explore key enzymes or organisms that are responsible for the synthesis of key intermediates of celastrol or site-specific functionalization of celastrol.

\section{Taking Advantage of Nano/micro-systems}

An ideal drug delivery system maintains the drug within a desired therapeutic range after a single dose, and/or target the drug to a specific region while simultaneously lowering the systemic levels of the drug. Many different systems and strategies have been evaluated for drug targeting to tumors over the years. In order to prolong blood circulation, "Stealth" systems of PEG is the most effective approach to achieve stability and improve longcirculation effect (Chen et al., 2016). In addition, the nanocarriers can also be used to deliver drugs through surface modification by binding the target molecules to the highly expressed receptors on the surface of tumor cells (Kim et al., 2019). It selectively recognizes specific molecules in disease tissues and improve therapeutic index while reducing serious side effects on normal healthy tissues. Common targeted modification molecules include folic acid (Prasad et al., 2018), hyaluronic acid (Huang and Huang, 2018), peptide (Xiao et al., 2019; Yi et al., 2020), transferrin (Zhang Y. et al., 2018), biotin (Li K. et al., 2019), etc.

In order to overcome delivery barriers, nanocarriers can be designed to vary with the tumor microenvironment, including charge reversal, shell detachment, size transition, etc (Sun et al., 2017). Moreover, by adjusting the release response mechanism and release rate of drugs under different stimuli, the nanocarriers can control the sequence and time schedule of drug combination therapy, so as to achieve more accurate drug delivery process and improve the effect and specificity of combined action (Zhu et al., 2017). The drug release behavior can be realized in different stimulant responses in tumor therapy, such as $\mathrm{pH}$ (Wang et al., 2017), hypoxia (Kumari et al., 2020), reduction (Xie and Liu, 2020), enzyme (Shan et al., 2019), temperature (Jommanee et al., 2018), ultrasound (Xia et al., 2018), etc.

Endogenous nanocarriers, as compared with synthetic nanoformulations, have shown promising results in enhancing drug delivery and therapeutic efficacy because of their native biocompatibility in vivo (Batrakova and Kim, 2015). For example, exosomes are emerging as an effective therapeutic tool for various pathologies, which cannot be treated by conventional medicine. These sub-micron-sized vesicles are secreted by different cell types and participate in intercellular communication by fusing with the recipient cell membrane and thus delivering their payload (genetic information and proteins) to the cell (Betzer et al., 2017). In addition, some exosomes also exhibit an increased capacity to escape degradation or clearance by the immune system (Luan et al., 2017). Therefore, exosomes are ideal natural nanocarriers for clinical application of celastrol because of their naturally biocompatible characteristics.
Despite many developments on multifunctional theranostic nano-systems for diagnostic imaging and tumor therapy, we need pay more attention to the attempts on the design of 'self-reporter nano-systems' which can not only be used for drug delivery, but also as a real-time feedback of in vivo tumor response to treatment.

\section{CONCLUSION}

Natural products continue to serve as an important and invaluable source of new drug discovery. Celastrol is one of the most potent chemotherapeutic agents effective against a variety of cancers including breast, liver, lung and ovarian cancer. The poor physicochemical characteristics of the celastrol are major challenges in the formulation development and as a result there are very limited formulation options in clinic for this drug. Besides, the used celastrol which has been found to cause various adverse effects including infertility toxicity, cardiotoxicity, hepatotoxicity, hematopoietic system toxicity and nephrotoxicity due to weak targeting. Therefore, the researchers tried different strategies to overcome these obstacles. This review systematically summarizes the combination chemotherapy of celastrol in different cancers, including combination with chemotherapeutic agents, tumor necrosis factor superfamily, active ingredients of Traditional Chinese Medicine, IR and nucleic acid. Successful combinations can enhance the therapeutic efficiency of celastrol. Moreover, lowering the dosage used of celastrol by combining it with agents effectively reduces their related adverse effects. These results highlight it is beneficial to improve the deficiency of celastrol and expand its application range. Furthermore, structural modification could promote physical and chemical properties and pharmacokinetics by improving stability, solubility, selectivity and biological activity. Additionally, nano/micro-medicine formulations endeavor to improve both the toxicity profile and therapeutic efficacy relative to the conventional drug formulation. Nano/microsystems encapsulated celastrol have been employed to improve celastrol aqueous solubility, chemical stability, efficacy and safety, prolong celastrol biodistribution, reduce side effects of celastrol.

Accordingly, the following three suggestions are proposed for further research on celastrol. 1) A complete pharmacokinetic profiling and in vitro-in vivo correlation for the drug combinations, needs to be drawn to further move up the ladder. 2) The development of celastrol-based drug combination would also be a useful strategy, such as the use of a protective agent to reduce its toxicity, the combination of celastrol with other anticancer agents to gain an increased anticancer activity to overcome the development of drug resistance. 3) The clinical translations of combination antitumor therapy and structural modification will be also investigated extensively, and the well-designed nanocarriers and nanoformulations with simple manufacturing process, good reproducibility and easy quality control will attract more attentions, which eventually lead to the rapid clinical translation of celastrol. 


\section{AUTHOR CONTRIBUTIONS}

JS and JL wrote the first draft. JS, JL and ZX performed literature survey and data extraction. LC and RL provided the organization and framework of the article. CZ, FG, JZ and CF provided critical revisions. All authors approved the final version of the manuscript for submission.

\section{REFERENCES}

Aggarwal, B. B., Gupta, S. C., and Kim, J. H. (2012). Historical perspectives on tumor necrosis factor and its superfamily: 25 years later, a golden journey. Blood 119, 651-665. doi:10.1182/blood-2011-04-325225

An, N., Li, H. Y., and Zhang, X. M. (2015). Growth inhibitive effect of betulinic acid combined with tripterine on MSB-1 cells and its mechanism. Poult. Sci. 94, 2880-2886. doi:10.3382/ps/pev267

Aqil, F., Kausar, H., Agrawal, A. K., Jeyabalan, J., Kyakulaga, A.-H., Munagala, R., et al. (2016). Exosomal formulation enhances therapeutic response of celastrol against lung cancer. Exp. Mol. Pathol. 101, 12-21. doi:10.1016/j.yexmp.2016.05. 013

Ashton, J. C. (2015). Drug combination studies and their synergy quantification using the chou-talalay method-letter. Cancer Res. 75, 2400. doi:10.1158/00085472.can-14-3763

Avila-Carrasco, L., Majano, P., Sánchez-Toméro, J. A., Selgas, R., López-Cabrera, M., Aguilera, A., et al. (2019). Natural plants compounds as modulators of epithelial-to-mesenchymal transition. Front. Pharmacol. 10, 715. doi:10.3389/ fphar.2019.00715

Bai, J.-P., Shi, Y.-L., Fang, X., and Shi, Q.-X. (2003). Effects of demethylzeylasteral and celastrol on spermatogenic cell $\mathrm{Ca} 2+$ channels and progesterone-induced sperm acrosome reaction. Eur. J. Pharmacol. 464, 9-15. doi:10.1016/s00142999(03)01351-7

Baran, I., Ionescu, D., Filippi, A., Mocanu, M. M., Iftime, A., Babes, R., et al. (2014). Novel insights into the antiproliferative effects and synergism of quercetin and menadione in human leukemia Jurkat T cells. Leuk. Res. 38, 836-849. doi:10. 1016/j.leukres.2014.04.010

Batrakova, E. V., and Kim, M. S. (2015). Using exosomes, naturally-equipped nanocarriers, for drug delivery. J. Contr. Release 219, 396-405. doi:10.1016/j. jconrel.2015.07.030

Bernabeu, E., Cagel, M., Lagomarsino, E., Moretton, M., and Chiappetta, D. A. (2017). Paclitaxel: what has been done and the challenges remain ahead. Int. J. Pharm. 526, 474-495. doi:10.1016/j.ijpharm.2017.05.016

Betzer, O., Perets, N., Angel, A., Motiei, M., Sadan, T., Yadid, G., et al. (2017). In in vivo neuroimaging of exosomes using gold nanoparticles. ACS Nano 11, 10883-10893. doi:10.1021/acsnano.7b04495

Boridy, S., Le, P. U., Petrecca, K., and Maysinger, D. (2014). Celastrol targets proteostasis and acts synergistically with a heat-shock protein 90 inhibitor to kill human glioblastoma cells. Cell Death Dis. 5, e1216. doi:10.1038/cddis.2014. 182

Cagel, M., Grotz, E., Bernabeu, E., Moretton, M. A., and Chiappetta, D. A. (2017). Doxorubicin: nanotechnological overviews from bench to bedside. Drug Discov. Today 22, 270-281. doi:10.1016/j.drudis.2016.11.005

Cai, X. H., Jin, J., and He, M. H. (2016). Advances in structural modifications of celastrol. J. Org. Chem. 2016, 172-182. doi:10.3998/ark.5550190.p009.540

Cao, X., Hu, Y., Luo, S., Wang, Y., Gong, T., Sun, X., et al. (2019). Neutrophilmimicking therapeutic nanoparticles for targeted chemotherapy of pancreatic carcinoma. Acta Pharm. Sin. B 9, 575-589. doi:10.1016/j.apsb.2018.12.009

Cascão, R., Carvalho, T., Goncalves, J., Moita, L. F., and Fonseca, J. E. (2017). AB0096 efficacy and safety of oral administration of pure celastrol in aia rats. In European Congress of Rheumatology. Ann. Rheum. Dis. 76, 1080. doi:10.1136/ annrheumdis-2017-eular.2868

Cascão, R., Fonseca, J. E., and Moita, L. F. (2017). Celastrol: a spectrum of treatment opportunities in chronic diseases. Front. Med. 4, 69. doi:10.3389/ fmed.2017.00069

Cha, Z., Cheng, J., Xiang, H., Qin, J., He, Y., Peng, Z., et al. (2019). Celastrol enhances TRAIL-induced apoptosis in human glioblastoma via the death

\section{FUNDING}

This research was supported by China Postdoctoral Science Foundation (2017M612930), Distinguished Young Science and Technology Talents of the Science and Technology Department of Sichuan Province (2019JDJQ0049) and National Natural Science Foundation of China (81973662).

receptor pathway. Cancer Chemother. Pharmacol. 84, 719-728. doi:10.1007/ s00280-019-03900-8

Chadalapaka, G., Jutooru, I., and Safe, S. (2012). Celastrol decreases specificity proteins (Sp) and fibroblast growth factor receptor-3 (FGFR3) in bladder cancer cells. Carcinogenesis 33, 886-894. doi:10.1093/carcin/bgs102

Chang, M.-Y., Hsieh, C.-Y., Lin, C.-Y., Chen, T.-D., Yang, H.-Y., Chen, K.-H., et al. (2018). Effect of celastrol on the progression of polycystic kidney disease in a Pkd1-deficient mouse model. Life Sci. 212, 70-79. doi:10.1016/j.lfs.2018. 09.047

Chen, M., Rose, A. E., Doudican, N., Osman, I., and Orlow, S. J. (2009). Celastrol synergistically enhances temozolomide cytotoxicity in melanoma cells. Mol. Cancer Res. 7, 1946-1953. doi:10.1158/1541-7786.MCR-09-0243

Chen, S., Yang, K., Tuguntaev, R. G., Mozhi, A., Zhang, J., Wang, P. C., et al. (2016). Targeting tumor microenvironment with PEG-based amphiphilic nanoparticles to overcome chemoresistance. Nanomed. Nanotechnol. Biol. Med. 12, 269-286. doi:10.1016/j.nano.2015.10.020

Chen, X. Y., Hu, X. X., Hu, J. J., Qiu, Z. P., Yuan, M., and Zheng, G. H. (2020). Celastrol-loaded galactosylated liposomes effectively inhibit AKT/c-Mettriggered rapid hepatocarcinogenesis in mice. Mol. Pharm. 3, 738-747. doi:10.1021/acs.molpharmaceut.9b00428

Chen, Y., Zhou, L., Yuan, L., Zhang, Z. H., Liu, X., and Wu, Q. (2012). Formulation, characterization, and evaluation of in vitro skin permeation and in vivo pharmacodynamics of surface-charged tripterine-loaded nanostructured lipid carriers. Int. J. Nanomed. 7, 3023-3032. doi:10.2147/IJN.S32476

Chiang, K.-C., Tsui, K.-H., Chung, L.-C., Yeh, C.-N., Chang, P.-L., Chen, W.-T., et al. (2014). Topoisomerase inhibitors modulate gene expression of B-Cell translocation gene 2 and prostate specific antigen in prostate carcinoma cells. PLoS One 9, e89117-e93151. doi:10.1371/journal.pone.0093151

Choi, J. Y., Ramasamy, T., Kim, S. Y., Kim, J., Ku, S. K., Youn, Y. S., et al. (2016). PEGylated lipid bilayer-supported mesoporous silica nanoparticle composite for synergistic co-delivery of axitinib and celastrol in multi-targeted cancer therapy. Acta Biomater. 39, 94-105. doi:10.1016/j.actbio.2016.05.012

Cleren, C., Calingasan, N. Y., Chen, J., and Beal, M. F. (2005). Celastrol protects against MPTP- and 3-nitropropionic acid-induced neurotoxicity. J. Neurochem. 94, 995-1004. doi:10.1111/j.1471-4159.2005.03253.x

Corson, T. W., and Crews, C. M. (2007). Molecular understanding and modern application of traditional medicines: triumphs and trials. Cell 130, 769-774 doi:10.1016/j.cell.2007.08.021

Dai, Y., DeSano, J. T., Meng, Y., Ji, Q., Ljungman, M., Lawrence, T. S., et al. (2009). Celastrol potentiates radiotherapy by impairment of DNA damage processing in human prostate cancer. Int. J. Radiat. Oncol. Biol. Phys. 74, 1217-1225. doi:10.1016/j.ijrobp.2009.03.057

Davenport, A., Frezza, M., Shen, M., Ge, Y., Huo, C., Chan, T. H., et al. (2010). Celastrol and an EGCG pro-drug exhibit potent chemosensitizing activity in human leukemia cells. Int. J. Mol. Med. 25, 465-470. doi:10.3892/ ijmm_00000366.

Dou, B., Wahid, M. A., Wang, Z., Xie, C., Thakkar, A., Prabhu, S., et al. (2017). Triptolide and celastrol loaded silk fibroin nanoparticles show synergistic effect against human pancreatic cancer cells. Nanoscale 9, 11739-11753. doi:10.1039/ c7nr03016a

Divya, T., Velavan, B., and Sudhandiran, G. (2018). Regulation of transforming growth factor- $\beta /$ Smad-mediated epithelial-Mmesenchymal transition by celastrol provides protection against bleomycin-induced pulmonary fibrosis. Basic Clin. Pharmacol. Toxicol. 123, 122-129. doi:10.1111/bcpt.12975

Duan, J., Zhan, J.-C., Wang, G.-Z., Zhao, X.-C., Huang, W.-D., and Zhou, G.-B. (2019). The red wine component ellagic acid induces autophagy and exhibits anti-lung cancer activity in vitro and in vivo. J. Cell Mol. Med. 23, 143-154. doi: $10.1111 /$ jcmm.13899 
El Chediak, A., Shamseddine, A., Bodgi, L., Obeid, J. P., Geara, F., et al. (2017). Optimizing tumor immune response through combination of radiation and immunotherapy. Med. Oncol. 34, 165. doi:10.1007/s12032-017-1025-z

Freag, M. S., Saleh, W. M., and Abdallah, O. Y. (2018a). Laminated chitosan-based composite sponges for transmucosal delivery of novel protamine-decorated tripterine phytosomes: ex-vivo mucopenetration and in-vivo pharmacokinetic assessments. Carbohydr. Polym. 188, 108-120. doi:10.1016/j.carbpol.2018.01.095

Freag, M. S., Saleh, W. M., and Abdallah, O. Y. (2018b). Self-assembled phospholipid-based phytosomal nanocarriers as promising platforms for improving oral bioavailability of the anticancer celastrol. Int. J. Pharm. 535, 18-26. doi:10.1016/j.ijpharm.2017.10.053

Figueiredo, S. A. C., Salvador, J. A. R., Cortés, R., and Cascante, M. (2017). Novel celastrol derivatives with improved selectivity and enhanced antitumour activity: design, synthesis and biological evaluation. Eur. J. Med. Chem. 138, 422-437. doi:10.1016/j.ejmech.2017.06.029

Gao, Y., Zhou, S., Pang, L., Yang, J., Li, H. J., Huo, X., et al. (2019). Celastrol suppresses nitric oxide synthases and the angiogenesis pathway in colorectal cancer. Free Radic. Res. 53, 324-334. doi:10.1080/10715762. 2019.1575512

Ge, P., Niu, B., Wu, Y., Xu, W., Li, M., Sun, H., et al. (2020). Enhanced cancer therapy of celastrol in vitro and in vivo by smart dendrimers delivery with specificity and biosafety. Chem. Eng. J. 383, 123228. doi:10.1016/j.cej.2019. 123228

Ghosh, A. K., and Brindisi, M. (2015). Organic carbamates in drug design and medicinal chemistry. J. Med. Chem. 58, 2895-2940. doi:10.1021/jm501371s

Gulijk, M. V., Dammeijer, F., Aerts, J. G. J. V., and Vroman, H. (2018). Combination strategies to optimize efficacy of dendritic cell-based immunotherapy. Front. Immunol. 9, 2759. doi:10.3389/fimmu.2018.02759

Guo, J. Q., Huang, X. M., Wang, H., and Yang, H. J. (2015). Celastrol induces autophagy by targeting AR/miR-101 in prostate cancer cells. PLoS One 10, e0140745. doi:10.1371/journal.pone.0140745

Guo, L., Luo, S., Du, Z. W., Zhou, M. L., Li, P. W., Fu, Y., et al. (2017). Targeted delivery of celastrol to mesangial cells is effective against mesangioproliferative glomerulonephritis. Nat. Commun. 8, 878. doi:10.1038/s41467-017-00834-8

Guo, M., Qu, D., Qin, Y., Chen, Y., Liu, Y., Huang, M., et al. (2019). Transferrinfunctionalized microemulsions coloaded with coix seed oil and tripterine deeply penetrate to improve cervical cancer therapy. Mol. Pharm. 16, 4826-4835. doi:10.1021/acs.molpharmaceut.9b00717

Haasteren, J. V., Hyde, S. C., and Gill, D. R. (2018). Lessons learned from lung and liver in-vivo gene therapy: implications for the future. Expet Opin. Biol. Ther. 18, 959-972. doi:10.1080/14712598.2018.1506761.

Hansen, J., Palmfeldt, J., Vang, S., Corydon, T. J., Gregersen, N., and Bross, P. (2011). Quantitative proteomics reveals cellular targets of celastrol. PLoS One 6, e26634. doi:10.1371/journal.pone.0026634

Hayashi, A., Horiuchi, A., Kikuchi, N., Hayashi, T., Fuseya, C., Suzuki, A., et al. (2010). Type-specific roles of histone deacetylase (HDAC) overexpression in ovarian carcinoma: HDAC1 enhances cell proliferation and HDAC3 stimulates cell migration with downregulation of E-cadherin. Int. J. Cancer 127, 1332-1346. doi:10.1002/ijc.25151

He, D., Xu, Q., Yan, M., Zhang, P., Zhou, X. J., Zhang, Z. Y., et al. (2009). The NF-kappa $\mathrm{B}$ inhibitor, celastrol, could enhance the anti-cancer effect of gambogic acid on oral squamous cell carcinoma. BMC Cancer 9, 343. doi:10.1186/1471-2407-9-343

Hou, W., Liu, B., and Xu, H. (2020). Celastrol: progresses in structuremodifications, structure-activity relationships, pharmacology and toxicology. Eur. J. Med. Chem. 189, 112081. doi:10.1016/j.ejmech.2020.112081

Hoy, S. M. (2014). Albumin-bound paclitaxel: a review of its use for the first-line combination treatment of metastatic pancreatic cancer. Drugs 74, 1757-1768. doi:10.1007/s40265-014-0291-8

Hu, Y., Chen, X., Xu, Y., Han, X., Wang, M., Gong, T., et al. (2019). Hierarchical assembly of hyaluronan coated albumin nanoparticles for pancreatic cancer chemoimmunotherapy. Nanoscale 11, 16476-16487. doi:10.1039/c9nr03684a

Huang, G., and Huang, H. (2018). Hyaluronic acid-based biopharmaceutical delivery and tumor-targeted drug delivery system. J. Contr. Release 278, 122-126. doi:10.1016/j.jconrel.2018.04.015

Huang, W., Chen, L., Kang, L., Jin, M., Sun, P., Xin, X., et al. (2017). Nanomedicinebased combination anticancer therapy between nucleic acids and smallmolecular drugs. Adv. Drug Deliv. Rev. 115, 82-97. doi:10.1016/j.addr.2017. 06.004
Huang, Y., Zhou, D., Hang, T., Wu, Z., Liu, J., Xu, Q., et al. (2012). Preparation, characterization, and assessment of the antiglioma effects of liposomal celastrol. Anti Cancer Drugs 23, 515-524. doi:10.1097/CAD.0b013e3283514b68

Huntzinger, E., and Izaurralde, E. (2011). Gene silencing by microRNAs: contributions of translational repression and mRNA decay. Nat. Rev. Genet. 12, 99-110. doi:10.1038/nrg2936

Jang, S. Y., Jang, S.-W., and Ko, J. (2011). Celastrol inhibits the growth of estrogen positive human breast cancer cells through modulation of estrogen receptor $\alpha$. Cancer Lett. 300, 57-65. doi:10.1016/j.canlet.2010.09.006

Jin, C. H., Wu, Z. J., Wang, L. L., Kanai, Y., and He, X. (2019). CYP450s-activity relations of celastrol to interact with triptolide reveal the reasons of hepatotoxicity of Tripterygium wilfordii. Molecules 24, 2162. doi:10.3390/ molecules24112162.

Jiang, F., Wang, H.-J., Bao, Q.-C., Wang, L., Jin, Y.-H., Zhang, Q., et al. (2016). Optimization and biological evaluation of celastrol derivatives as Hsp90-Cdc37 interaction disruptors with improved druglike properties. Bioorg. Med. Chem. 24, 5431-5439. doi:10.1016/j.bmc.2016.08.070

Jiang, H.-L., Jin, J.-Z., Wu, D., Xu, D., Lin, G.-F., and Yu, H. . (2013). Celastrol exerts synergistic effects with PHA-665752 and inhibits tumor growth of c-Metdeficient hepatocellular carcinoma in vivo. Mol. Biol. Rep. 40, 4203-4209. doi:10.1007/s11033-013-2501-y

Jiang, Q.-W., Cheng, K.-J., Mei, X.-L., Qiu, J.-G., Zhang, W.-J., Xue, Y.-Q., et al. (2015). Synergistic anticancer effects of triptolide and celastrol, two main compounds from thunder god vine. Oncotarget 6, 32790-32804. doi:10. 18632/oncotarget.5411

Jobby, R., Jha, P., Yadav, A. K., and Desai, N. (2018). Biosorption and biotransformation of hexavalent chromium [Cr(VI)]: a comprehensive review. Chemosphere 207, 255-266. doi:10.1016/j.chemosphere.2018.05.050

Jommanee, N., Chanthad, C., and Manokruang, K. (2018). Preparation of injectable hydrogels from temperature and $\mathrm{pH}$ responsive grafted chitosan with tuned gelation temperature suitable for tumor acidic environment. Carbohydr. Polym. 198, 486-494. doi:10.1016/j.carbpol.2018.06.099

Jun, H. Y., Kim, T.-H., Choi, J. W., Lee, Y. H., Lee, K. K., and Yoon, K.-H. (2017). Evaluation of connectivity map-discovered celastrol as a radiosensitizing agent in a murine lung carcinoma model: feasibility study of diffusion-weighted magnetic resonance imaging. PLoS One 12, e0178204. doi:10.1371/journal. pone.0178204

Kang, T., Zhu, Q., Wei, D., Feng, J., Yao, J., Jiang, T., et al. (2017). Nanoparticles coated with neutrophil membranes can effectively treat cancer metastasis. ACS Nano. 11, 1397-1411. doi:10.1021/acsnano.6b06477

Song, R., Manu, K. A., Chen, L., Li, F., Rajendran, P., Subramaniam, A., et al. (2011). Celastrol inhibits tumor cell proliferation and promotes apoptosis through the activation of c-Jun N-terminal kinase and suppression of PI3 K/Akt signaling pathways. Apoptosis 16, 1028-1041. doi:10.1007/s10495011-0629-6

Kashyap, D., Sharma, A., Tuli, H. S., Sak, K., Mukherjee, T., and Bishayee, A. (2018). Molecular targets of celastrol in cancer: recent trends and advancements. Crit. Rev. Oncol. Hematol. 128, 70-81. doi:10.1016/j. critrevonc.2018.05.019

Khojasteh, S. C., Miller, G. P., Mitra, K., and Rietjens, I. M. C. M. (2018). Biotransformation and bioactivation reactions - 2017 literature highlights. Drug Metabol. Rev. 50, 221-255. doi:10.1080/03602532.2018.1473875

Kim, M. W., Jeong, H. Y., Kang, S. J., Jeong, I. H., Choi, M. J., You, Y. M., et al. (2019). Anti-EGF receptor aptamer-guided co-delivery of anti-cancer siRNAs and quantum dots for theranostics of triple-negative breast cancer. Theranostics 9, 837-852. doi:10.7150/thno.30228

Kim, S. H., Kang, J. G., Kim, C. S., Ihm, S. H., Choi, M. G., Yoo, H. J., et al. (2017). Cytotoxic effect of celastrol alone or in combination with paclitaxel on anaplastic thyroid carcinoma cells. Tumour. Biol. 39, 1010428317698369. doi: $10.1177 / 1010428317698369$

Klaić, L., Morimoto, R. I., and Silverman, R. B. (2012). Celastrol analogues as inducers of the heat shock response. design and synthesis of affinity probes for the identification of protein targets. ACS Chem. Biol. 7, 928-937. doi:10.1021/cb200539u.

Klaić, L., Trippier, P. C., Mishra, R. K., Morimoto, R. I., and Silverman, R. B. (2011) Remarkable stereospecific conjugate additions to the Hsp90 inhibitor celastrol. J. Am. Chem. Soc. 133, 19634-19637. doi:10.1021/ja208359a

Konieczny, J., Jantas, D., Lenda, T., Domin, H., Czarnecka, A., Kuter, K., et al. (2014). Lack of neuroprotective effect of celastrol under conditions of 
proteasome inhibition by lactacystin in in vitro and in vivo studies: implications for Parkinson's disease. Neurotox. Res. 26, 255-273. doi:10.1007/s12640-0149477-9

Kumari, R., Sunil, D., and Ningthoujam, R. S. (2020). Hypoxia-responsive nanoparticle based drug delivery systems in cancer therapy: an up-to-date review. J. Contr. Release 319, 135-156. doi:10.1016/j.jconrel.2019.12.041

Kusy, S., Ghosn, E. E. B., Herzenberg, L. A., and Contag, C. H. (2012). Development of $\mathrm{B}$ cells and erythrocytes is specifically impaired by the drug celastrol in mice. PLoS One 7, e35733. doi:10.1371/journal.pone.0035733

Lagoa, R., Silva, J., Rodrigues, J. R., and Bishayee, A. (2020). Advances in phytochemical delivery systems for improved anticancer activity. Biotechnol. Adv. 38, 107382. doi:10.1016/j.biotechadv.2019.04.004

Landewé, R. B. M., and van der Heijde, D. (2014). Comment on: 'comparison of Tripterygium wilfordii Hook F with methotrexate in the treatment of active rheumatoid arthritis (TRIFRA): a randomised, controlled clinical trial' by Qianwen et al. Ann. Rheum. Dis. 73, e62. doi:10.1136/annrheumdis-2014-206124

Lee, H. E., Lee, J. Y., Yang, G., Kang, H. C., Cho, Y. Y., Lee, H. S., et al. (2019). Inhibition of NLRP3 inflammasome in tumor microenvironment leads to suppression of metastatic potential of cancer cells. Sci. Rep. 9, 12277. doi:10. 1038/s41598-019-48794-x

Lee, J. H., Choi, K. J., Seo, W. D., Jang, S. Y., Kim, M., and Lee, B. W. (2011). Enhancement of radiation sensitivity in lung cancer cells by celastrol is mediated by inhibition of Hsp90. Int. J. Mol. Med. 27, 441-446. doi:10. 3892/ijmm.2011.601

Li, G., Liu, D., Zhang, Y., Qian, Y., Zhang, H., Guo, S., et al. (2013). Celastrol inhibits lipopolysaccharide-stimulated rheumatoid fibroblast-like synoviocyte invasion through suppression of TLR4/NF-kB-mediated matrix metalloproteinase-9 expression. PLoS One 8, e68905. doi:10.1371/journal.pone.0068905

Li, H., Fan, Y., Yang, F., Zhao, L., and Cao, B. (2018). The coordinated effects of apatinib and tripterine on the proliferation, invasiveness and apoptosis of human hepatoma Hep3B cells. Oncol. Lett. 16, 353-361. doi:10.3892/ol.2018.8656

Li, H.-Y., Zhang, J., Sun, L.-L., Li, B.-H., Gao, H.-L., and Xie, T. (2015). Celastrol induces apoptosis and autophagy via the ROS/JNK signaling pathway in human osteosarcoma cells: an in vitro and in vivo study. Cell Death Dis. 6, e1604. doi:10. 1038/cddis.2014.5434529

Li, J., and Hao, J. (2019). Treatment of neurodegenerative diseases with bioactive components of Tripterygium wilfordii. Am. J. Chin. Med. 47, 769-785. doi:10. $1142 / \mathrm{s} 0192415 \times 1950040 \mathrm{x}$

Li, J., Wang, X., Jiang, H., Lu, X., Zhu, Y., and Chen, B. (2011). New strategy of photodynamic treatment of $\mathrm{TiO} 2$ nanofibers combined with celastrol for HepG2 proliferation in vitro. Nanoscale 3, 3115-3122. doi:10.1039/c1nr10185d

Li, J., Wu, Y., Wang, D., Zou, L., Fu, C., Zhang, J., et al. (2019). Oridonin synergistically enhances the anti-tumor efficacy of doxorubicin against aggressive breast cancer via pro-apoptotic and anti-angiogenic effects. Pharmacol. Res. 146, 104313. doi:10.1016/j.phrs.2019.104313

Li, K., Dong, W., Liu, Q., Lv, G., Xie, M., Sun, X., et al. (2019). A biotin receptortargeted silicon(IV) phthalocyanine for in vivo tumor imaging and photodynamic therapy. J. Photochem. Photobiol. B Biol. 190, 1-7. doi:10. 1016/j.jphotobiol.2018.09.001

Li, N., Xu, M., Bao, N., Shi, W., Li, Q., Zhang, X., et al. (2018). Discovery of novel NO-releasing celastrol derivatives with Hsp90 inhibition and cytotoxic activities. Eur. J. Med. Chem. 160, 1-8. doi:10.1016/j.ejmech.2018.10.013

Li, P., Zhou, X., Qu, D., Guo, M., Fan, C., Zhou, T., et al. (2017). Preliminary study on fabrication, characterization and synergistic anti-lung cancer effects of selfassembled micelles of covalently conjugated celastrol-polyethylene glycolginsenoside Rh2. Drug Deliv. 24, 834-845. doi:10.1080/10717544.2017.1326540

Li, R., He, Y., Zhang, S., Qin, J., and Wang, J. (2018). Cell membrane-based nanoparticles: a new biomimetic platform for tumor diagnosis and treatment. Acta Pharm. Sin. B 8, 14-22. doi:10.1016/j.apsb.2017.11.009

Li, X., Ding, J., Li, N., Liu, W., Ding, F., Zheng, H., et al. (2019). Synthesis and biological evaluation of celastrol derivatives as anti-ovarian cancer stem cell agents. Eur. J. Med. Chem. 179, 667-679. doi:10.1016/j.ejmech.2019.06.086

Li, Y., Li, Z., Wu, J. G., Li, J., Yao, L. M., and Zhang, Y. Y. (2012). Antitumor activity of celastrol nanoparticles in a xenograft retinoblastoma tumor model. Int. J. Nanomed. 7, 2389-2398. doi:10.2147/IJN.S29945

Li, Y. J., Sun, Y. X., Hao, R. M., Wu, P., Zhang, L. J., and Ma, X. (2018). miR-33a-5p enhances the sensitivity of lung adenocarcinoma cells to celastrol by regulating mTOR signaling. Int. J. Oncol. 52, 1328-1338. doi:10.3892/ijo.2018.4276
Li, Z., Guo, Z., Chu, D., Feng, H., Zhang, J., and Zhu, L. (2020). Effectively suppressed angiogenesis-mediated retinoblastoma growth using celastrol nanomicelles. Drug Deliv. 27, 358-366. doi:10.1080/10717544.2020.1730522

Li, Z., Yao, L., Li, J., Zhang, W., Wu, X., and Liu, Y. (2012). Celastrol nanoparticles inhibit corneal neovascularization induced by suturing in rats. Int. J. Nanomed. 7, 1163-1173. doi:10.2147/IJN.S27860

Li, Z., Zhang, J., Tang, J., and Wang, R. (2016). Celastrol increases osteosarcoma cell lysis by $\gamma \delta \mathrm{T}$ cells through up-regulation of death receptors. Oncotarget 7 , 84388-84397. doi:10.18632/oncotarget.12756

Lin, L., Sun, Y., Wang, D., Zheng, S., Zhang, J., and Zheng, C. (2015). Celastrol ameliorates ulcerative colitis-related colorectal cancer in mice via suppressing inflammatory responses and epithelial-mesenchymal transition. Front. Pharmacol. 6, 320. doi:10.3389/fphar.2015.00320

Lipsky, P., and Tao, X. (1997). A potential new treatment for rheumatoid arthritis: Thunder god vine. Semin. Arthritis Rheum. 26, 713-723. doi:10.1016/s00490172(97)80040-6

Liu, B. (2017). A novel nucleolin aptamer-celastrol conjugate (NACC) with super antitumor activity on advanced pancreatic cancer, Kowloon Tong: Hong Kong Baptist University.

Liu, C., Zhang, C., Wang, W., Yuan, F., He, T., Chen, Y., et al. (2019). Integrated metabolomics and network toxicology to reveal molecular mechanism of celastrol induced cardiotoxicity. Toxicol. Appl. Pharmacol. 383, 114785. doi:10.1016/j.taap.2019.114785

Liu, J., Lee, J., Salazar Hernandez, M. A., Mazitschek, R., and Ozcan, U. (2015). Treatment of obesity with celastrol. Cell 161, 999-1011. doi:10.1016/j.cell.2015. 05.011

Liu, Q., Chen, F., Hou, L., Shen, L., Zhang, X., and Wang, D. (2018). Nanocarriermediated chemo-immunotherapy arrested cancer progression and induced tumor dormancy in desmoplastic melanoma. ACS Nano. 12, 7812-7825. doi:10.1021/acsnano. 8 b01890

Liu, X. H., Zhao, P. Y., Wang, X. J., Wang, L., Zhu, Y. J., Song, Y. D., et al. (2019). Celastrol mediates autophagy and apoptosis via the ROS/JNK and Akt/mTOR signaling pathways in glioma cells. J. Exp. Clin. Cancer Res. 38, 184. doi:10.1186/ s13046-019-1173-4

Liu, Y., Crawford, B. M., and Vo-Dinh, T. (2018). Gold nanoparticles-mediated photothermal therapy and immunotherapy. Immunotherapy 10, 1175-1188. doi:10.2217/imt-2018-0029

Liu, Z., Ma, L., Wen, Z.-S., Hu, Z., Wu, F.-Q., Li, W., et al. (2014). Cancerous inhibitor of PP2A is targeted by natural compound celastrol for degradation in non-smallcell lung cancer. Carcinogenesis 35, 905-914. doi:10.1093/carcin/bgt395

Lu, L., Shi, W., Deshmukh, R. R., Long, J., Cheng, X., Ji, W., et al. (2014). Tumor necrosis factor- $\alpha$ sensitizes breast cancer cells to natural products with proteasome-inhibitory activity leading to apoptosis. PLoS One 9, e113783. doi:10.1371/journal.pone.0113783

Luan, X., Sansanaphongpricha, K., Myers, I., Chen, H., Yuan, H., and Sun, D. (2017). Engineering exosomes as refined biological nanoplatforms for drug delivery. Acta Pharmacol. Sin. 38, 754-763. doi:10.1038/aps.2017.12

Mahbub, A. A., Maitre, Le., C. L.Haywood-Small, S. L., Cross, N. A., and JordanMahy, N. (2015). Polyphenols act synergistically with doxorubicin and etoposide in leukaemia cell lines. Cell Death Dis. 1, 15043. doi:10.1038/ cddiscovery.2015.43

Matokanovic, M., Barisic, K., Filipovic-Grcic, J., and Maysinger, D. (2013). Hsp70 silencing with siRNA in nanocarriers enhances cancer cell death induced by the inhibitor of Hsp90. Eur. J. Pharmaceut. Sci. 50, 149-158. doi:10.1016/j.ejps. 2013.04.001

Maysinger, D., Moquin, A., Choi, J., Kodiha, M., and Stochaj, U. (2018). Gold nanourchins and celastrol reorganize the nucleo- and cytoskeleton of glioblastoma cells. Nanoscale 10, 1716-1726. doi:10.1039/c7nr07833a

Metselaar, D. S., Meel, M. H., Benedict, B., Waranecki, P., Koster, J., and Kaspers, G. J. L. (2019). Celastrol-induced degradation of FANCD2 sensitizes pediatric high-grade gliomas to the DNA-crosslinking agent carboplatin. EBioMedicine 50, 81-92. doi:10.1016/j.ebiom.2019.10.062

Mo, R., Jiang, T. Y., DiSanto, R., Tai, W. Y., and Gu, Z. (2014). ATP-triggered anticancer drug delivery. Nat. Commun. 5, 3364. doi:10.1038/ncomms4364

Nazim, U. M., Yin, H., and Park, S. Y. (2019). Autophagy flux inhibition mediated by celastrol sensitized lung cancer cells to TRAILinduced apoptosis via regulation of mitochondrial transmembrane potential and reactive oxygen species. Mol. Med. Rep. 19, 984-993. doi:10.3892/mmr.2018.9757. 
Niemelä, E., Desai, D., Nkizinkiko, Y., Eriksson, J. E., and Rosenholm, J. M. (2015). Sugar-decorated mesoporous silica nanoparticles as delivery vehicles for the poorly soluble drug celastrol enables targeted induction of apoptosis in cancer cells. Eur. J. Pharm. Biopharm. 96, 11-21. doi:10.1016/j.ejpb.2015.07.009

Onyeabor, F., Paik, A., Kovvasu, S., Ding, B., Lin, J., Wahid, M. A., et al. (2019). Optimization of preparation and preclinical pharmacokinetics of celastrolencapsulated silk fibroin nanoparticles in the rat. Molecules 24, 3271. doi:10. 3390/molecules24183271.

Pang, C., Luo, J., Liu, C., Wu, X., and Wang, D. (2018). Synthesis and biological evaluation of a series of novel celastrol derivatives with amino acid chain. Chem. Biodivers. 15, e1800059. doi:10.1002/cbdv.201800059

Pham, A.-N., Blower, P. E., Alvarado, O., Ravula, R., Gout, P. W., and Huang, Y. (2010). Pharmacogenomic approach reveals a role for the xc-cystine/glutamate antiporter in growth and celastrol resistance of glioma cell lines. J. Pharmacol. Exp. Therapeut. 332, 949-958. doi:10.1124/jpet.109.162248

Prasad, R., Agawane, S. B., Chauhan, D. S., Srivastava, R., and Selvaraj, K. (2018). In in vivo examination of folic acid-conjugated gold-silica nanohybrids as contrast agents for localized tumor diagnosis and biodistribution. Biocon. Chem. 29, 4012-4019. doi:10.1021/acs.bioconjchem.8b00522

Qi, X., Qin, J., Ma, N., Chou, X., and Wu, Z. (2014). Solid self-microemulsifying dispersible tablets of celastrol: formulation development, charaterization and bioavailability evaluation. Int. J. Pharm. 472, 40-47. doi:10.1016/j.ijpharm. 2014.06.019

Qin, Y., Liu, T., Guo, M., Liu, Y., Liu, C., and Chen, Y. (2020). Mild-heat-inducible sequentially released liposomal complex remodels the tumor microenvironment and reinforces anti-breast-cancer therapy. Biomater. Sci. 8, 3916-3925. doi:10.1039/d0bm00498g

Qu, D., Wang, L., Qin, Y., Guo, M., Guo, J., and Huang, M. . (2018). Non-triggered sequential-release liposomes enhance anti-breast cancer efficacy of STS and celastrol-based microemulsion. Biomater. Sci. 6, 3284-3299. doi:10.1039/ c8bm00796a

Raja, S. M., Clubb, R. J., Ortega-Cava, C., Williams, S. H., Bailey, T. A., Duan, L., et al. (2011). Anticancer activity of celastrol in combination with ErbB2targeted therapeutics for treatment of ErbB2-overexpressing breast cancers. Canc. Biol. Ther. 11, 263-276. doi:10.4161/cbt.11.2.13959

Rajendran, P., Li, F., Shanmugam, M. K., Kannaiyan, R., Goh, J. N., Wong, K. F., et al. (2012). Celastrol suppresses growth and induces apoptosis of human hepatocellular carcinoma through the modulation of STAT3/JAK2 signaling cascade in vitro and in vivo. Cancer Prev. Res. 5, 631-643. doi:10.1158/19406207.capr-11-0420

Sanna, V., Chamcheu, J. C., Pala, N., Mukhtar, H., Sechi, M., and Siddiqui, I. A. (2015). Nanoencapsulation of natural triterpenoid celastrol for prostate cancer treatment. Int. J. Nanomed. 10, 6835-6846. doi:10.2147/IJN.S93752

Sanmamed, M. F., and Chen, L. (2018). A paradigm shift in cancer immunotherapy: from enhancement to normalization. Cell 175, 313-326. doi:10.1016/j.cell.2018.09.035

Shan, W.-G., Wang, H.-G., Chen, Y., Wu, R., Wen, Y.-T., Zhang, L.-W., et al. (2017). Synthesis of 3- and 29-substituted celastrol derivatives and structureactivity relationship studies of their cytotoxic activities. Bioorg. Med. Chem. Lett 27, 3450-3453. doi:10.1016/j.bmcl.2017.05.083

Shan, W.-G., Wang, H.-G., Wu, R., Zhan, Z.-J., and Ma, L.-F. (2019). Synthesis and anti-tumor activity study of water-soluble PEG-celastrol coupling derivatives as self-assembled nanoparticles. Bioorg. Med. Chem. Lett. 29, 685-687. doi:10. 1016/j.bmcl.2019.01.042

Shanmugam, M. K., Ahn, K. S., Lee, J. H., Kannaiyan, R., Mustafa, N., Manu, K. A., et al. (2018). Celastrol attenuates the invasion and migration and augments the anticancer effects of bortezomib in a xenograft mouse model of multiple myeloma. Front. Pharmacol. 9, 365. doi:10.3389/fphar.2018.00365

Shi, H. 2015. Synthesis and anti-cancer evaluation of analogues related to celastrol and wilforol B. Zhejiang, Chiina: Zhejiang University of Technology.

Singh, Y., Meher, J. G., Raval, K., Khan, F. A., Chaurasia, M., Jain, N. K., et al. (2017). Nanoemulsion: concepts, development and applications in drug delivery. J. Contr. Release 252, 28-49. doi:10.1016/j.jconrel.2017.03.008

Song, J., Shi, F., Zhang, Z., Zhu, F., Xue, J., Tan, X., et al. (2011). Formulation and evaluation of celastrol-loaded liposomes. Molecules 16, 7880-7892. doi:10.3390/ molecules 16097880

Sreeramulu, S., Gande, S. L., Göbel, M., and Schwalbe, H. (2009). Molecular mechanism of inhibition of the human protein complex Hsp90-Cdc37, a kinome chaperone-cochaperone, by triterpene celastrol. Angew. Chem. Int. Ed. 48, 5853-5855. doi:10.1002/anie.200900929

Sun, B., Chen, Y., Yu, H., Wang, C., Zhang, X., Zhao, H., et al. (2019). Photodynamic PEG-coated ROS-sensitive prodrug nanoassemblies for coreshell synergistic chemo-photodynamic therapy. Acta Biomater. 92, 219-228. doi:10.1016/j.actbio.2019.05.008

Sun, H., Liu, X., Xiong, Q., Shikano, S., and Li, M. (2006). Chronic inhibition of cardiac Kir2.1 and HERG potassium channels by celastrol with dual effects on both ion conductivity and protein trafficking. J. Biol. Chem. 281, 5877-5884. doi:10.1074/jbc.M600072200

Sun, M., Tang, Y., Ding, T., Liu, M., and Wang, X. (2014). Inhibitory effects of celastrol on rat liver cytochrome P450 1A2, 2C11, 2D6, 2E1 and 3A2 activity. Fitoterapia 92, 1-8. doi:10.1016/j.fitote.2013.10.004

Sun, Q. H., Zhou, Z. X., Qiu, N. S., and Shen, Y. Q. (2017). Rational design of cancer nanomedicine: nanoproperty integration and synchronization. Adv. Mater. 29, 1606628. doi:10.1002/adma.201606628

Tan, Y., Zhu, Y., Zhao, Y., Wen, L., Meng, T., Liu, X., et al. (2018). Mitochondrial alkaline $\mathrm{pH}$-responsive drug release mediated by celastrol loaded glycolipid-like micelles for cancer therapy. Biomaterials 154, 169-181. doi:10.1016/j. biomaterials.2017.07.036

Tang, K., Huang, J., Pan, J., Zhang, X., and Lu, W. (2015). Design, synthesis and biological evaluation of $\mathrm{C}(6)$-indole celastrol derivatives as potential antitumor agents. RSC Adv. 5, 19620-19623. doi:10.3390/molecules 190710177

Tang, K., Huang, Q., Zeng, J., Wu, G., Huang, J., and Pan, J. (2014). Design, synthesis and biological evaluation of $\mathrm{C}(6)$-modified celastrol derivatives as potential antitumor agents. Molecules 19, 10177-10188. doi:10.3390/ molecules190710177

Tang, W.-J., Wang, J., Tong, X., Shi, J.-B., Liu, X.-H., and Li, J. (2015). Design and synthesis of celastrol derivatives as anticancer agents. Eur. J. Med. Chem. 95, 166-173. doi:10.1016/j.ejmech.2015.03.039

Wang, G., Xiao, Q., Wu, Y., Wei, Y. J., Jing, Y., Cao, X. R., et al. (2019). Design and synthesis of novel celastrol derivative and its antitumor activity in hepatoma cells and antiangiogenic activity in zebrafish. J. Cell. Physiol. 234, 16431-16446. doi:10.1002/jcp.28312

Wang, L.-P., Chen, B. X., Sun, Y., Chen, J. P., Huang, S., and Liu, Y. Z. (2019). Celastrol inhibits migration, proliferation and transforming growth factor- $\beta 2$ induced epithelial-mesenchymal transition in lens epithelial cells. Int. J. Ophthalmol. 12, 1517-1523. doi:10.18240/ijo.2019.10.01

Wang, Q., Yu, X., Li, F., Lv, X., Fu, X., and Gu, H. (2019). Efficacy of celastrol combined with cisplatin in enhancing the apoptosis of U-2OS osteosarcoma cells via the mitochondrial and endoplasmic reticulum pathways of apoptosis. Oncol. Lett. 17, 3305-3313. doi:10.3892/ol.2019.10007

Wang, T., Wang, D., Liu, J., Feng, B., Zhou, F., Zhang, H., et al. (2017). Aciditytriggered ligand-presenting nanoparticles to overcome sequential drug delivery barriers to tumors. Nano Lett. 17, 5429-5436. doi:10.1021/acs.nanolett.7b02031

Wang, Y., Du, H., and Zhai, G. (2014). Recent advances in active hepatic targeting drug delivery system. Curr. Drug Targets 15, 573-599. doi:10.2174/ 1389450115666140309232100

Wang, Y., Liu, Q., Chen, H., You, J., Peng, B., and Cao, F. (2018). Celastrol improves the therapeutic efficacy of EGFR-TKIs for non-small-cell lung cancer by overcoming EGFR T790M drug resistance. Anti Cancer Drugs 29, 748-755. doi:10.1097/CAD.0000000000000647

Wang, Z., Dabrosin, C., Yin, X., Fuster, M. M., Arreola, A., and Rathmell, W. K. (2015). Broad targeting of angiogenesis for cancer prevention and therapy. Semin. Canc. Biol., 35 (Suppl. 1), S224-S243. doi:10.1016/j.semcancer.2015.01.001

Wei, W., Wu, S., Wang, X., Sun, C. K.-W., Yang, X., Yan, X., et al. (2014). Novel celastrol derivatives inhibit the growth of hepatocellular carcinoma patientderived xenografts. Oncotarget 5, 5819. doi:10.18632/oncotarget.2171

Weng, W. H., and Goel, A. (2020). Curcumin and colorectal cancer: an update and current perspective on this natural medicine. Semin. Canc. Biol. [Epub ahead of print] doi:10.1016/j.semcancer.2020.02.011

Wu, J., Ding, M., Mao, N., Wu, Y., Wang, C., Yuan, J., et al. (2017). Celastrol inhibits chondrosarcoma proliferation, migration and invasion through suppression CIP2A/c-MYC signaling pathway. J. Pharmacol. Sci. 134, 22-28. doi:10.1016/j.jphs.2016.12.007

Wu, M., Chen, W., Yu, X., Ding, D., Zhang, W., and Hua, H. (2018). Celastrol aggravates LPS-induced inflammation and injuries of liver and kidney in mice. Am. J. Transl. Res. 10, 2078-2086. 
Xia, J., Wang, J., Wang, X., Qian, M., Zhang, L., and Chen, Q. (2018). Ultrasoundresponsive nanoparticulate for selective amplification of chemotherapeutic potency for ablation of solid tumors. Bioconjugate Chem. 29, 3467-3475. doi:10.1021/acs.bioconjchem.8b00626

Xiao, W., Ma, W., Wei, S., Li, Q., Liu, R., Carney, R. P., et al. (2019). High-affinity peptide ligand LXY30 for targeting $\alpha 3 \beta 1$ integrin in non-small cell lung cancer. J. Hematol. Oncol. 12, 56. doi:10.1186/s13045-019-0740-7

Xiao, Y., Liu, J., Guo, M., Zhou, H., Jin, J., Liu, J., et al. (2018). Synergistic combination chemotherapy using carrier-free celastrol and doxorubicin nanocrystals for overcoming drug resistance. Nanoscale 10, 12639-12649. doi:10.1039/c8nr02700e

Xie, P., and Liu, P. (2020). pH-responsive surface charge reversal carboxymethyl chitosan-based drug delivery system for $\mathrm{pH}$ and reduction dual-responsive triggered DOX release. Carbohydr. Polym. 236, 116093. doi:10.1016/j.carbpol. 2020.116093

Xu, H., and Liu, B. (2019). Triptolide-targeted delivery methods. Eur. J. Med. Chem. 164, 342-351. doi:10.1016/j.jejmech.2018.12.058

Xu, M., Li, N., Zhao, Z., Shi, Z., Sun, J., and Chen, L. (2019). Design, synthesis and antitumor evaluation of novel celastrol derivatives. Eur. J. Med. Chem. 174, 265-276. doi:10.1016/j.ejmech.2019.04.050

Xue, J., Zhao, Z., Zhang, L., Xue, L., Shen, S., Wen, Y., et al. (2017). Neutrophilmediated anticancer drug delivery for suppression of postoperative malignant glioma recurrence. Nat. Nanotechnol. 12, 692-700. doi:10.1038/ nnano.2017.54

Yadav, P., Jaswal, V., Sharma, A., Kashyap, D., Tuli, H. S., Garg, V. K., et al. (2018). Celastrol as a pentacyclic triterpenoid with chemopreventive properties. Pharm. Patent Anal.t 7, 155-167. doi:10.4155/ppa-2017-0035

Yan, Y. Y., Bi, H., Zhang, W., Wen, Q., Liu, H., Li, J. X., et al. (2017). Downregulation and subcellular distribution of HER2 involved in MDAMB-453 breast cancer cell apoptosis induced by lapatinib/celastrol combination. J. BUON. 22, 644-651.

Yang, H., Chen, D., Cui, Q. C., Yuan, X., and Dou, Q. P. (2006). Celastrol, a triterpene extracted from the Chinese "Thunder of God Vine," is a potent proteasome inhibitor and suppresses human prostate cancer growth in nude mice. Cancer Res. 66, 4758-4765. doi:10.1158/0008-5472.CAN-05

Yi, A., Sim, D., Lee, Y. J., Sarangthem, V., and Park, R. W. (2020). Development of elastin-like polypeptide for targeted specific gene delivery in vivo. J. Nanobiotechnol. 18, 15. doi:10.1186/s12951-020-0574-z

Yin, J., Wang, P., Yin, Y., Hou, Y., and Song, X. (2017). Optimization on biodistribution and antitumor activity of tripterine using polymeric nanoparticles through RES saturation. Drug Deliv. 24, 1891-1897. doi:10. 1080/10717544.2017.1410260

Yuan, L., Liu, C., Chen, Y., Zhang, Z., Zhou, L., and Qu, D. (2013). Antitumor activity of tripterine via cell-penetrating peptide-coated nanostructured lipid carriers in a prostate cancer model. Int. J. Nanomed. 8, 4339-4350. doi:10.2147/IJN.S51621

Yuan, Y. Y., Gu, Z. P., Shi, Q. X., Qin, G. W., Xu, R. S., and Cao, L. (1995). In vitro inhibition of celastrol on spermatozoa fertilization ability of guinea pig. Yao Xue Xue Bao 30, 331-335 [in Chinese].

Zeng, J. F., Pan, J. F., Li, B. Y., Zhu, Q., Fang, T., and Ni, H. Y. (2012). Water-soluble triterpenephenol compounds having antitumor activity and the preparation thereof. World Intellectual Property Organization.

Zhang, H.-J., Zhang, G.-R., Piao, H.-R., and Quan, Z.-S. (2018). Synthesis and characterisation of celastrol derivatives as potential anticancer agents. J. Enzym. Inhib. Med. Chem. 33, 190-198. doi:10.1080/14756366.2017.1404590

Zhang, J., Li, C.-Y., Xu, M.-j., Wu, T., Chu, J.-H., Liu, S.-J., et al. (2012). Oral bioavailability and gender-related pharmacokinetics of celastrol following administration of pure celastrol and its related tablets in rats. J. Ethnopharmacol. 144, 195-200. doi:10.1016/j.jep.2012.09.005

Zhang, J., Li, J., Shi, Z., Yang, Y., Xie, X., Lee, S. M., et al. (2017). pH-sensitive polymeric nanoparticles for co-delivery of doxorubicin and curcumin to treat cancer via enhanced pro-apoptotic and anti-angiogenic activities. Acta Biomater. 58, 349-364. doi:10.1016/j.actbio.2017.04.029

Zhang, J. M., Wang, L., Chan, H. F., Xie, W., Chen, S., He, C. W., et al. (2017). Codelivery of paclitaxel and tetrandrine via iRGD peptide conjugated lipidpolymer hybrid nanoparticles overcome multidrug resistance in cancer cells. Sci. Rep. 7, 46057. doi:10.1038/srep46057
Zhang, Q., Tian, X., and Cao, X. (2019). Transferrin-functionalised microemulsion co-delivery of $\beta$-elemene and celastrol for enhanced anti-lung cancer treatment and reduced systemic toxicity. Drug Deliv. and Transl. Res. 9, 667-678. doi:10. 1007/s13346-019-00623-4

Zhang, R., Chen, Z., Wu, S.-S., Xu, J., Kong, L.-C., and Wei, P. (2019). Celastrol enhances the anti-liver cancer activity of sorafenib. Med. Sci. Mon. Int. Med. J. Exp. Clin. Res. 25, 4068-4075. doi:10.12659/MSM.914060

Zhang, T., Li, Y., Yu, Y., Zou, P., Jiang, Y., and Sun, D. (2009). Characterization of celastrol to inhibit hsp90 and cdc37 interaction. J. Biol. Chem. 284, 35381-35389. doi:10.1074/jbc.M109.051532

Zhang, X., Zhang, T., Zhou, X., Liu, H., Sun, H., Ma, Z., et al. (2014). Enhancement of oral bioavailability of tripterine through lipid nanospheres: preparation, characterization, and absorption evaluation. J. Pharmaceut. Sci. 103, 1711-1719. doi:10.1002/jps.23967

Zhang, Y., Sun, T., and Jiang, C. (2018). Biomacromolecules as carriers in drug delivery and tissue engineering. Acta Pharm. Sin. B 8, 34-50. doi:10.1016/j.apsb.2017.11.005

Zhao, Y., Tan, Y., Meng, T., Liu, X., Zhu, Y., Hong, Y., et al. (2018). Simultaneous targeting therapy for lung metastasis and breast tumor by blocking the NF- $\kappa \mathrm{B}$ signaling pathway using celastrol-loaded micelles. Drug Deliv. 25, 341-352. doi:10.1080/10717544.2018.1425778

Zhao, Z., Zhu, J., Quan, H., Wang, G., Li, B., Zhu, W., et al. (2016). X66, a novel $\mathrm{N}$-terminal heat shock protein 90 inhibitor, exerts antitumor effects without induction of heat shock response. Oncotarget 7, 29648-29663. doi:10.18632/ oncotarget. 8818

Zheng, L., Fu, Y., Zhuang, L., Gai, R., Ma, J., Lou, J., et al. (2014). Simultaneous NF$\kappa \mathrm{B}$ inhibition and E-cadherin upregulation mediate mutually synergistic anticancer activity of celastrol and SAHAin vitroandin vivo. Int. J. Caner 135, 1721-1732. doi:10.1002/ijc.28810

Zhou, X., Seto, S. W., Chang, D., Kiat, H., Razmovski-Naumovski, V., Chan, K., et al. (2016). Synergistic effects of chinese herbal medicine: a comprehensive review of methodology and current research. Front. Pharmacol. 7, 201. doi:10. 3389/fphar.2016.00201

Zhou, X., Yu, R., Cao, X., Zhang, Z.-R., and Deng, L. (2019). Bio-mimicking nanoparticles for targeted therapy of malignant melanoma. J. Biomed. Nanotechnol. 15, 993-1004. doi:10.1166/jbn.2019.2739

Zhou, Y. X., and Huang, Y. L. (2009). Antiangiogenic effect of celastrol on the growth of human glioma: an in vitro and in vivo study. Chin. Med. J. 122, 1666-1673.

Zhu, H., Ding, W.-J., Wu, R., Weng, Q.-J., Lou, J.-S., Jin, R.-J., et al. (2010a). Synergistic anti-cancer activity by the combination of TRAIL/APO-2L and celastrol. Cancer Invest. 28, 23-32. doi:10.3109/07357900903095664

Zhu, H., Liu, X.-W., Ding, W.-J., Xu, D.-Q., Zhao, Y.-C., Lu, W., et al. (2010b). Upregulation of death receptor 4 and 5 by celastrol enhances the anti-cancer activity of TRAIL/Apo-2L. Cancer Lett. 297, 155-164. doi:10.1016/j.canlet.2010.04.030

Zhu, H., Yang, W., He, L.-j., Ding, W.-j., Zheng, L., Liao, S.-d., et al. (2012). Upregulating Noxa by ER stress, celastrol exerts synergistic anti-cancer activity in combination with ABT-737 in human hepatocellular carcinoma cells. PLoS One 7, e52333. doi:10.1371/journal.pone.0052333

Zhu, W., Yu, H., Zhang, L.-J., Wu, B., Wang, C.-X., Wang, Q., et al. (2017). Redoxtriggered activation of nanocarriers for mitochondria-targeting cancer chemotherapy. Nanoscale 9, 17044-17053. doi:10.1039/c7nr06130g

Zhu, W.-J., Yang, S.-D., Qu, C.-X., Zhu, Q.-I., Chen, W.-I., Li, F., et al. (2017). Lowdensity lipoprotein-coupled micelles with reduction and $\mathrm{pH}$ dual sensitivity for intelligent co-delivery of paclitaxel and siRNA to breast tumor. Int. J. Nanomed. 12, 3375-3393. doi:10.2147/ijn.s126310

Conflict of Interest: The authors declare that the research was conducted in the absence of any commercial or financial relationships that could be construed as a potential conflict of interest.

Copyright $\odot 2020 \mathrm{Shi}, \mathrm{Li}, \mathrm{Xu}$, Chen, Luo, Zhang, Gao, Zhang and Fu. This is an open-access article distributed under the terms of the Creative Commons Attribution License (CC BY). The use, distribution or reproduction in other forums is permitted, provided the original author(s) and the copyright owner(s) are credited and that the original publication in this journal is cited, in accordance with accepted academic practice. No use, distribution or reproduction is permitted which does not comply with these terms. 